Article

\title{
Preparation for the doctoral defense: methods and relation to defense outcome and perception
}

\author{
Eva O.L. Lantsoght $1,2^{*}$
}

1 Universidad San Francisco de Quito, Quito, Ecuador; elantsoght@usfq.edu.ec
2 Delft University of Technology, Delft, the Netherlands: E.O.L.Lantsoght@tudelft.nl
* Correspondence: elantsoght@usfq.edu.ec; Tel.: +593-2-297-1700 ext. 1186

\begin{abstract}
The doctoral defense is an important step towards obtaining the doctoral degree. As such, preparing for the event is necessary. Anecdotal evidence highlights that there is a wide variety of ways in which doctoral candidates prepare for the defense. In this work, I want to explore if there is a relation between the way in which a doctoral candidate prepares for the defense and two important aspects of the defense: the outcome of the defense, and the student perception during and after the defense. For this purpose, I first reviewed the literature on the topic of the preparation for the doctoral defense. Then, I carried out an international survey on the doctoral defense and analyzed the data of the 204 completed surveys with respect to the preparation for the defense using quantitative and qualitative methods. The methods I used included the statistical tests of the correlation between on one hand the preparation and on the other hand the defense outcome and student perception. I used inductive thematic analysis of the open-ended survey questions to gain deeper insight in the way candidates prepared for their defense. I found that candidates most often prepare by making their presentation, reading their thesis, and practicing. The most effective measure is the mock defense, followed by a preparatory course. Reading blogs, books, and chapters is a less effective preparation measure. The conclusion of this work is that doctoral candidates need to understand the format of their defense in order to be able to prepare properly, and that universities should explore either individual pathways to the defense or pilots using a mock defense and/or preparatory course to give their doctoral candidates the necessary tools to prepare for their doctoral defense.
\end{abstract}

Keywords: academia; affective dimension; doctoral education; mock defense; qualitative analysis; quantitative analysis; viva; viva voce

\section{Introduction}

At universities where the doctoral thesis is defended orally, this doctoral defense is an important step towards obtaining the doctoral degree. However, the doctoral defense is not studied much in an international context. Because the doctoral defense is often considered the culmination of years of work, but at the same time shrouded in mystery, it is important to study the doctoral defense, and how doctoral candidates prepare for the defense.

It is also important to broaden the discussion about the doctoral defense to an international comparative level. Indeed, most existing work about the defense studies the defense only from a national or local (i.e. single university) perspective. The vast majority of work on the doctoral defense has been carried out in the anglophone sphere: United Kingdom [1-10], Australia (where the thesis is assessed in a written form) [11], New Zealand [12], and the United States [13, 14]. At the same time, there is an interest in the European Union to work towards a standardized format of the defense [13-19].

Depending on the country and defense format, the doctoral defense may influence the assessment of the thesis and the amount of revisions required [8], and failing the $\mathrm{PhD}$ after an unsuccessful defense is possible in some universities (60\% of 20 British universities analyzed) [20]. Therefore, it is important for doctoral candidates to prepare properly 
for the event. A first step in the preparation lies in understanding the defense format, as different expectations are associated with different defense formats [21]. A second step in the preparation consists of understanding the breadth and depth of preparation necessary. Here, anecdotal evidence is contradictory. In the testimonies about the doctoral defense that I have gathered on my blog over the past decade, the advice from former PhD candidates varies widely. Some former candidates recommend an extensive preparation that involves preparing the presentation, having a mock defense, practicing with typical defense questions and preparing answers, rereading emails from committee members and notes from meetings with them, and marking up the thesis [22], whereas others recommend to be confident and not practice the presentation too much [23].

In the past, some authors have recommended certain types of preparation. In particular, they have focused on the mock defense, which allows doctoral candidates to practice the defense in advance [24], or courses to help doctoral candidates understand the expectations around the defense and how to prepare for the defense [6]. Anecdotal evidence [22] also indicates that many doctoral candidates read testimonies about the defense, advice posts, and list of potential questions on the internet and in books and book chapters on the topic.

In this research, I want to answer the following research question: How does the preparation for the doctoral defense influence the defense in terms of outcome and student perception? Studying this research question allows us to evaluate the effectiveness of potential university-wide courses prior to the defense, or requiring a mock defense, as well as to evaluate the effectiveness of additional reading about the defense in anticipation of the event. This work can be considered a first step towards better preparation policies in doctoral schools internationally.

\section{Literature review}

\subsection{Preparation of the doctoral defense}

Only a handful studies in the literature deal with preparation of the doctoral defense. Watts [24] remarked that, because of the unpredictability and mystery around the doctoral defense (and in the case of this research, the viva voce from the United Kingdom), "development of effective strategies aimed at a positive outcome requires judicious attention." This advice aligns with the cautionary account of Remenyi [1] who detailed a viva that followed the rulebook but where the candidate almost failed as a result of letting down his intellectual guard. It could be argued here that the candidate did not understand the purpose and the expected behavior correctly, and that better preparation could have avoided such a situation.

A crucial element of preparation that all authors agree upon is to reread the thesis [24]. Being fully familiar with the contents of the thesis is the first step in being able to defend the research. It also serves the purpose of preparing to demonstrate authorship. Research into the guidelines of 20 universities in the UK [20] showed that confirming that the doctoral candidate actually did the work is often one of the purposes of the doctoral defense. As such, it is necessary that the doctoral candidate can clearly demonstrate that they wrote the thesis and understand fully their work. The second step in this preparation involves finding potential topics for debate during the defense, and critically analyzing the strengths and weaknesses of the work [24].

Charting the ways in which doctoral candidates prepare for the defense, Share [25] found that in the context of the UK viva, the preparation was as follows: $73 \%$ relied on supervisor advice, $71 \%$ considered presentations at conferences as preparation, $53 \%$ presented at internal seminars, 47\% read PhD advice books, 25\% had a mock viva, 10\% relied on family advice, and $7 \%$ attended viva preparation workshops.

One action that is recommended in the literature is the use of a course for doctoral candidates before the defense. This recommendation resulted from analyzing the sentiments of doctoral candidates towards the defense and their knowledge about it [6]. The research involved 16 focus groups, each consisting of between 10 and 16 students. The 
students in these focus groups reflected on their feelings (positive and negative) in anticipation towards the defense, and what they know and don't know about the defense. One of the findings of analyzing the input from the students in the focus groups was that some students do not properly understand the requirements or format of the defense. In particular, some students wrongly identified the nature of the defense as a quiz or a friendly chat. In addition, some students were confused about the possible outcome of the defense, the length of time of the defense, the regulations and rules of conduct during the defense, and the role and procedures for the appointment of the examiners (in the United Kingdom). Another surprising outcome is that the main source of information for those about to take the doctoral defense is friends who already passed their defense.

Using the information about the sentiments of the doctoral candidates about the defense and their knowledge about it, Wellington [6] gave recommendations on what to include in a preparatory course for the doctoral defense. He also remarked that such a course is valuable, as the participants in his focus groups had indicated that it would help them in their preparation. Since the data analysis showed that many students are confused about the purpose and mechanics of the defense, a course to clear up these confusions would be necessary. A particular topic that a course should address relates to the expected conduct during the defense. Of course, this conduct is a difficult topic, as it deals with the interaction between the candidate and committee members, and below the surface, various factors (sociodemographic, cultural, and more [26]) play an important role. At the same time, to clear up misconceptions from doctoral candidates about what to expect during the defense, Wellington [6] recommends doctoral candidates to attend the defenses of their peers, where the defense format allows this.

A final element of preparation that is recommended in the literature is the use of a mock defense. Here, Watts [24] describes the variety of possible arrangements for a mock defense: from a practice run of the defense presentation to the research group and answering questions from colleagues, over a format in which the supervisor (and potentially other colleagues) ask the candidate critical questions to practice answering committee questions, to a format where the candidates is examined on a small section of the dissertation. From looking at these different formats of the mock defense, it was found that the most effective mock defense is one that is as similar to the real defense as possible [24], in terms of type, content, and setting. Making sure that the mock defense resembles the actual defense as closely as possible requires time and effort, and it also requires that all those who participate in the mock defense take their role seriously and enact the mock defense with the same rigor as a real defense. Watts [24] pointed out that while the questions during the mock and real defense will be different, it helps students understand the dynamics and challenges at play during the defense, and it may be particularly beneficial for students who are not native speakers.

To illustrate the importance of a mock defense, Manidis and Addo [3] present an autoethnography of Addo's practice run and final defense presentation. Addo received feedback on content and delivery from peers after the trial run, and used this input to refine and improve her delivery of the final defense presentation. She considered this interaction an essential formative experience, which the authors summarized as: "Amidst the pressure of today's increasingly public research context, participating, in practice, as practice, through practice, has become a pedagogical imperative."

\subsection{Research gap}

From the literature, I identified two gaps to be addressed with research. The first gap is that the defense has mostly been studied in a national context. As such, there is a need for research that addresses the defense through an international lens. The second gap in the literature is with regard to the relation between the preparation for the defense and the outcome of the defense in terms of result and in terms of how students experience their defense. The cited works look at potential forms of preparation (and in particular a preparatory course and the mock defense), but they do not link these suggestions to how 
students perceive the defense or to the outcome of the defense. This research addresses these gaps in the literature, and addresses as well preparatory reading on blogs and in books, as Share [25] highlighted that almost half of all doctoral candidates read PhD advice books in preparation for their defense.

\section{Materials and Methods}

\subsection{Survey design}

The data I used for studying the impact of the defense preparation on the outcome of the defense and the perception of students comes from a larger survey on the topic of the doctoral defense. The survey in particular looked at all aspects of defense formats, and the results on the relation between the defense format and student perception were published in a previous article [21]. The instrument and study received IRB exemption 2019139IN through Universidad San Francisco de Quito.

The first question of the survey explained the purpose of the research project and asked respondents for their informed consent. The survey itself consisted of 54 questions around three topics: sociodemographic aspects, elements of the defense format and defense preparation, and perception of the defense and its long-term impact. A variety of types of questions were used: multiple choice questions that either allowed one selection or all that apply (40 questions), sliding-scale ratings using an 11-point Likert scale [27] (7 questions on sentiments and 1 about defense format), short form open-ended questions (3 questions, on year of birth, year of defense, and email address), and long form open-ended questions (3 questions in total).

The five questions related to the preparation for the doctoral defense consisted of two open-ended question and three single-selection multiple-choice questions. The openended questions were "How did you prepare for your defense? Please summarize the actions you undertook to prepare for your defense." and "In hindsight, would you have prepared differently for the defense? Describe what you would have done differently." The multiple-choice questions were: 1) "Did you have a mock defense or other type of rehearsal", with answer options being "mock defense", "other type of practice", and "no practice", 2) "Did you attend a course to prepare for your defense?" with answer options being "Yes, course about the defense itself", "Yes, as part of another PhD course", and "No", and 3) "Did you read a book, a chapter, websites, blog posts... about the defense as part of your preparation? If so, which?" with answer options "Yes, the following" including a form to fill in the sources consulted, and " $\mathrm{No}^{\prime}$.

The first action recommended in the analyzed articles is to reread the thesis, and identify topics for discussion. Since this action is generally recommended, I did not include this action in the survey to evaluate the effectiveness of various preparatory steps.

The questions with regard to the defense outcome and length of the defense were single-selection multiple-choice questions. These questions were: 1) "What was the outcome of your doctoral defense?" with answer options "Passed", "Minor corrections", "Major corrections", "Switched fields", and "Dropped out", and 2) "How much time did the defense take?" with answer options "Less than 1 hour", "1 hour - 1.5 hours", "1.5 hours -2 hours", "2 hours -3 hours", and "More than 3 hours".

The questions with regard to student sentiment used sliding scales between 0 and 10 to rate the level of the sentiment $[2,25]$. These questions were: 1 ) "On a scale from $0-10$ how nervous were you before the defense, during the defense, and after the defense (but before receiving the outcome)" with a sliding scale between 0 (not nervous at all) and 10 (extremely nervous), 2) "On a scale from 0-10, how much did you enjoy your defense?" with a scale from 0 (not at all) to 10 (enjoyed it very much), 3) "On a scale from 0 to 10, how important did you perceive your defense?" with a scale from 0 (only a formality) to 10 (crucial to passing PhD examination), 4) "On a scale from 0-10, how difficult did you perceive the defense?" with a scale from 0 (extremely easy) to 10 (extremely difficult), 5) "On a scale from 0-10 how formal was your defense?" with a scale from 0 (very informal) to 10 (following strict protocol for procedures and language), 6) “On a scale from $0-10$ how 
serious were the defense proceedings?" with a scale from 0 (relaxed, space for humor) to 10 (very serious, no space for humor), and 7) "On a scale from 0-10, how valuable do you consider the oral $\mathrm{PhD}$ defense as part of the doctoral experience?" with a scale from 0 (not worth at all) to 10 (extremely valuable experience).

Two questions regarding student sentiment looked at the role of the committee. These multiple-choice questions were: 1) "Did you consider your committee fair?" and 2) "Did you consider your committee suitable for making a well-balanced assessment of your work?", both with answer options "yes", "to some extent", and "no". One multipleselections multiple-choice question looked at the purpose of the defense [20] through the question "How would you describe the purpose of your defense? Select all that apply." with options "examination", "ceremony", "celebration", "confirmation", "rite of passage", and "other" with space in a textbox for providing a description.

A final set of questions looked at the long-term impact of the doctoral defense on the sentiments of the candidate, using the four questions from [20]: 1) "How did your defense influence your perception of our academic competence?", "How did you defense influence your desire to continue to work in the sphere of your PhD research", "How did your defense influence your desire to work in academia", and "How did your defense influence your perception of the publishability of your research", with answer options for these four questions as " $X X$ increased after my defense", " $X X$ decreased after my defense", and " $X X$ was not affected by my defense", where XX stands for the aspect from the question.

\subsection{Analysis}

\subsubsection{Analysis methods}

I used the same analysis methods to study the relation between defense preparation and outcome as used to study the relation to the defense format [21] and the sociodemographic aspects [26]. This study used a combination of qualitative and quantitative methods.

To prepare the data for analysis, and after closing the survey, I first read all answers horizontally (all answers to one question) and vertically (full survey answers per respondent) to get a first insight into the responses. Then, after filtering out surveys that were empty or did not reach the final question, I developed the first report of the results and downloaded the data as an MS Excel sheet.

For the quantitative analysis, I used Matlab R2019a [28]. Using a coded m-file, I read in the various columns from the Excel sheet. Where necessary, I created additional columns in Excel to recode the input columns from text into numerical values. Then, my programmed routine sorted out the empty cells from the created vectors, carried out the statistical tests, and grouped data into breakdown tables. I also cross-checked these results with the breakdown option on the survey platform. The statistical tests that I used are the Wilcoxon rank sum test for cases where there are only two categories of a type of defense preparation, and the Kruskal-Wallis test when the analysis involved more than two categories of a type of defense preparation [29]. I considered a $p$-value of $<0.05$ as an indicator of correlation.

For the qualitative analysis, I used inductive thematic analysis [30-32]. For this purpose, I used the text analysis feature on the survey platform. The first step in this analysis was to read again all the answers to the open-ended question that I was about to analyze, to get an idea of possible themes. Then, I tagged topics to each of the responses individually. At the same time, I took notes in a notebook by hand about these topics, to develop the associated memo. In a next step, I looked at all the topics to check for potential overlap, duplication, or potential typing errors. Then, I started to sort these topics into parent categories of overarching themes. Finally, a few weeks later when writing the "results and analysis section" of this article, I read through the parent categories and subthemes again, and adjusted themes and topics where necessary. Finally, I exported the text analysis as .csv files for opening in MS Excel to develop the tables shown in this article. The exported results from the text analysis also included the information of the counts, so I rearranged 
the results from themes that were most often mentioned to those least often mentioned. Using this approach, the themes surfaced from the data of the survey and analysis procedure and were not influenced by any idea I may have had a priori.

\subsubsection{Analysis matrix}

For the part of the statistical tests in the data analysis, I developed the analysis matrix shown in Table 1. This table shows in one column the aspects of defense preparation ( 3 in total) and in the other column the aspects of defense outcome and student perception (16 in total). Between brackets I included the question number from the survey for reference. The total number of analyses of statistical tests is thus $3 \times 16=48$.

These statistical tests were carried out in Matlab R2019a. I set up one code (programmed as an .m file) for the relation between preparation of the defense and the aspects of defense outcome (defense outcome and length of the defense), and then one code for each aspect of preparation of the defense and all aspects of student perception, resulting in four separate files of code in total.

Table 1. Matrix of analysis between categories of defense preparation and categories of defense outcome and student perception.

\begin{tabular}{|c|c|c|}
\hline & Preparation of defense & Defense outcome and perception \\
\hline 1 & Mock defense (Q43) & Defense outcome (Q19) \\
\hline 2 & Preparation course (Q44) & Length of defense (Q26) \\
\hline 3 & $\begin{array}{c}\text { Preparatory reading } \\
(\mathrm{Q} 45)\end{array}$ & Eervousness (Q48) \\
\hline 4 & & Perceived fairness of committee (Q50) \\
\hline 5 & & Perceived committee suitability (Q51) \\
\hline 6 & & Perceived importance (Q52) \\
\hline 7 & & Difficulty of defense (Q53) \\
\hline 8 & & Formality of defense (Q54) \\
\hline 9 & & Seriousness of defense proceedings (Q55) \\
\hline 10 & & Purpose of defense (Q57) \\
\hline 11 & & Perceived academic competence after defense (Q59) \\
\hline 12 & & Desire to continue in field after defense (Q60) \\
\hline 13 & & Desire to remain in academia after defense (Q61) \\
\hline 14 & & Perceived publishability of research after defense (Q62) \\
\hline 15 & & Overall perception of defense as valuable experience \\
\hline 16 & & (Q63) \\
\hline
\end{tabular}

\subsection{Participants}

Participants filled out the survey on the online Qualtrics platform between July $13^{\text {th }}$ of 2020 and October $3^{\text {rd }}$ of 2020. They were recruited through social media and by email from my personal network, and thus represent a self-selecting convenience sample [33]. Given the exploratory nature of this work, using such a sample is considered not to hinder data collection and analysis. However, future and larger studies may want to use different sampling methods.

It took the respondents between 2.5 minutes and 81 hours to complete the survey (average $=39$ minutes and median $=10.6$ minutes). Since the respondents could return to the survey at any time, provided that they used the same IP address, those responses with longer times before completion most likely came from those who returned to the survey after a pause to complete the survey. 
Table 2. Characteristics of respondents in terms of sociodemographic aspects, broken down by outcome of the defense. Note that no respondents self-identified as "other/prefer not to say" gender. The results of the outcome of the defense are presented by breaking down the categories into the percentages that passed, had minor corrections, or major corrections, which allows comparison of different sociodemographic aspects in relation to defense outcome.

\begin{tabular}{|c|c|c|c|c|}
\hline & $\begin{array}{c}\text { Total } \\
n=204\end{array}$ & $\begin{array}{l}\text { Passed } \\
n=139\end{array}$ & $\begin{array}{c}\text { Minor corrections } \\
n=57\end{array}$ & $\begin{array}{c}\text { Major corrections } \\
n=7\end{array}$ \\
\hline Gender & $n=202$ & $n=138$ & $n=57$ & $n=7$ \\
\hline Male & $35.6 \%$ & $68.1 \%$ & $29.2 \%$ & $2.8 \%$ \\
\hline Female & $64.4 \%$ & $68.5 \%$ & $27.7 \%$ & $3.9 \%$ \\
\hline Ethnicity & $n=199$ & $n=135$ & $n=57$ & $n=7$ \\
\hline White & $72.4 \%$ & $66.7 \%$ & $28.5 \%$ & $4.9 \%$ \\
\hline Black or African American & $3.5 \%$ & $57.1 \%$ & $42.9 \%$ & $0.0 \%$ \\
\hline Asian & $8.0 \%$ & $68.8 \%$ & $31.3 \%$ & $0.0 \%$ \\
\hline Latinx/Hispanic & $6.5 \%$ & $69.2 \%$ & $30.8 \%$ & $0.0 \%$ \\
\hline First Nations & $0.5 \%$ & $100 \%$ & $0.0 \%$ & $0.0 \%$ \\
\hline Mixed & $2.0 \%$ & $50.0 \%$ & $50.0 \%$ & $0.0 \%$ \\
\hline Other & $7.0 \%$ & $85.7 \%$ & $14.3 \%$ & $0.0 \%$ \\
\hline Current employment & $n=202$ & $n=138$ & $n=57$ & $n=7$ \\
\hline Academia & $76.2 \%$ & $70.1 \%$ & $27.9 \%$ & $2.0 \%$ \\
\hline Industry and business & $13.9 \%$ & $60.7 \%$ & $32.1 \%$ & $7.1 \%$ \\
\hline Government & $4.0 \%$ & $62.5 \%$ & $25.0 \%$ & $12.5 \%$ \\
\hline Unemployed & $3.5 \%$ & $85.7 \%$ & $14.3 \%$ & $0.0 \%$ \\
\hline Other & $2.5 \%$ & $40.0 \%$ & $40.0 \%$ & $20.0 \%$ \\
\hline Age at the defense & $n=195$ & $n=134$ & $n=54$ & $n=7$ \\
\hline$<26$ & $2.6 \%$ & $80.0 \%$ & $20.0 \%$ & $0.0 \%$ \\
\hline $26-30$ & $39.5 \%$ & $67.5 \%$ & $27.3 \%$ & $5.2 \%$ \\
\hline $31-35$ & $31.3 \%$ & $70.5 \%$ & $27.9 \%$ & $1.6 \%$ \\
\hline $36-40$ & $13.3 \%$ & $69.2 \%$ & $26.9 \%$ & $3.8 \%$ \\
\hline $41-45$ & $5.6 \%$ & $54.5 \%$ & $36.4 \%$ & $9.1 \%$ \\
\hline $46-50$ & $4.1 \%$ & $87.5 \%$ & $12.5 \%$ & $0.0 \%$ \\
\hline$>50$ & $3.6 \%$ & $57.1 \%$ & $42.9 \%$ & $0.0 \%$ \\
\hline Field of study & $n=201$ & $n=137$ & $n=57$ & $n=7$ \\
\hline Life sciences & $22.9 \%$ & $76.1 \%$ & $21.7 \%$ & $2.2 \%$ \\
\hline Humanities and arts & $14.4 \%$ & $58.6 \%$ & $24.1 \%$ & $17.2 \%$ \\
\hline Social sciences & $29.9 \%$ & $70.0 \%$ & $30.0 \%$ & $0.0 \%$ \\
\hline STEM & $28.4 \%$ & $68.4 \%$ & $29.8 \%$ & $1.8 \%$ \\
\hline Multidisciplinary & $4.5 \%$ & $44.4 \%$ & $55.6 \%$ & $0.0 \%$ \\
\hline
\end{tabular}

The total number of respondents of the survey was 296. The anonymized dataset from the survey is provided in the public domain [34]. Of these responses, I filtered out 204 responses that were complete up to the last question, and I used only this filtered dataset for the analysis. The respondents were not required to answer each question, and for this reason I have included the $n$ of responses throughout this paper.

An overview of the sociodemographic characteristics of the respondents, broken down by outcome of the defense, is shown in Table 2. The characteristics that are included are: gender, ethnicity, current employment, age at defense, and field of study. The results are also broken down by outcome of the defense, into the categories "Passed", "Minor corrections", and "Major corrections". We can see from Table 2 that the majority of the respondents consider themselves as female $(64.4 \%)$, white $(72.4 \%)$, and employed in academia (76.2\%). Most of the respondents (70.8\%) were between 26 and 35 years of age at the time of their defense. The respondents are distributed among different fields of study, with the largest representation in the Social Sciences $(29.9 \%)$ and STEM $(28.4 \%)$ and the lowest representation in the Multidisciplinary field (4.5\%). 
The survey respondents represent an international sample with doctorates obtained in 31 different countries and residing in 34 different countries at the time of filling out the survey. The respondents represent all six inhabited continents. The most represented countries where the respondents obtained their doctorate are: the United States (33\%), the Netherlands (16\%), the United Kingdom (12\%), Canada (9\%), France (3\%), and Spain (3\%). The most represented countries where the respondents currently reside are: the United States (30\%), Ecuador (13\%), the Netherlands (13\%), the United Kingdom (9\%), and Canada $(8 \%)$.

\section{Results and analysis}

\subsection{Results of questionnaire}

Here, I present the outcomes of the survey questions with regard to the preparation for the defense. In [26, 35] further information about other parts of the survey can be found. With regard to the defense outcome, the results are as follows: $68.5 \%$ of participants passed, $28.0 \%$ had minor corrections, and 3.5\% had major corrections.

The length of the defense was less than 1 hour for $11.9 \%$ of the respondents, between 1 hour and 1.5 hours for $27.4 \%$, between 1.5 and 2 hours for $34.3 \%$, between 2 and 3 hours for $21.4 \%$, and longer than 3 hours for $5.0 \%$ of the respondents.

In terms of preparation for the defense, the largest group (42.6\% of participants) did not have any form of preparation. About a third (33.7\%) had a mock defense, and the remaining part $(23.8 \%)$ had another type of practice for their defense.

It is uncommon for PhD candidates to attend a course in preparation for the defense. The vast majority $(91.6 \%)$ of respondents were in this case. A small group (5.5\%) of respondents attended a course about the defense itself and the remaining group of respondents $(3.0 \%)$ received instruction as part of another PhD course.

The majority of respondents (77.2\%) also did not read a book, chapter, blog post, or website in preparation for the defense. Of those $(22.8 \%)$ who consulted written resources, 39 respondents specified the source they consulted. Using inductive thematic analysis of the text answers, I identified the parent categories in Table 3. Of those who consulted websites, most respondents mentioned that they used search terms in a search engine to find relevant websites and articles. Two resources that are mentioned in particular are the PhD viva guide from NUI Galway [36] as well as online discussions. For those who mentioned that they consulted blogs, the resources mentioned by the participants were: $\mathrm{PhD}$ Talk [37], Patter [38], Thesis Whisperer [39], GradHacker [40], The Professors is In [41], and Viva Survivors [42]. The book references listed were: How to get a PhD [43], The A-Z of the PhD Trajectory [44], How to Survive your PhD [45], How to survive your viva [46]. In the "other" category I collected comments of those who indicated they don't remember well or hint at general resources, as well as those who provided comments not directly related to resources, such as purchasing refreshments in preparation for the defense. For the parent category "all", the respondents read "anything I could get my hands on", as well as resources from all the categories mentioned in the question. Some respondents used resources provided by their university. In particular, respondents mentioned that they read documentation about the protocol, or documentation about the process, or verified the paperwork required for finishing. Those in the parent category of meetings either relied on meeting with their supervisor for information on how to prepare for the defense or went to watch defenses to understand better what is to be expected. Two respondents indicated that they checked out journal papers on the topic of the defense, and finally two respondents indicated that they relied on video resources: either PhD defenses that are on YouTube, or tips for the defense as presented on YouTube.

Table 3. Overview of parent categories from inductive thematic analysis of text answers for books, chapters, blog posts, websites, or other resources consulted prior to the defense. Total number of counts $=46$.

\begin{tabular}{lll} 
Topic & $\%$ & Count \\
\hline
\end{tabular}




\begin{tabular}{ccc}
\hline Websites & $28.3 \%$ & 13 \\
Blogs & $17.4 \%$ & 8 \\
Book & $15.2 \%$ & 7 \\
Other & $13.0 \%$ & 6 \\
All & $6.5 \%$ & 3 \\
University resources & $6.5 \%$ & 3 \\
Meetings & $4.4 \%$ & 2 \\
Papers & $4.4 \%$ & 2 \\
Video & $4.4 \%$ & 2 \\
\hline
\end{tabular}

An open-ended question addressed the preparation for the defense, through the following question "How did you prepare for your defense? Please summarize the actions you undertook to prepare for your defense." This questions received 171 responses, and I used inductive thematic analysis to identify the themes that surfaced from the answers. The themes were then organized into parent topics, as reported in Table 4.

The category with the most mentions is "presentation", which includes mentions of making the slides for the presentation, adjusting the presentation to the time limits as reflected by "For the first presentation I was supposed to deliver a 30 minute power point presentation and for the second more formal defense I prepared a written presentation that had to last 12 minutes. For the formal defense I intensely prepared myself for possible questions and my supervisor read and gave me feedback on the written document", preparing bullet points to remember topics to mention in the presentation, and preparing for the presentation in general.

Reading the thesis was also frequently mentioned. This parent category includes mentions of reading the thesis entirely, highlighting sections of the thesis, studying the thesis, preparing notes about the thesis, summarizing (chapters of) the thesis, as well as reading parts of the thesis.

The category of practicing includes the mock defense, practicing in front of colleagues, peers, or the supervisor, as well as general mentions of practicing for the defense. These actions are reflected by "Gave practice presentations to friends and colleagues who had already passed their defenses successfully." and "Mock defense with my lab and with friends who had already defended".

The category of research actions includes addressing issues with data analysis for example "Practiced my talk, addressed some data issues discovered in one chapter with committee by alerting them in advance", double checking of the data, reading the literature as explained by "Reading main papers related to my field of research, then developing a notes/highlights, then spent reading this over and over to make myself confident before viva.", reviewing the methodology and framework as explained by "Reviewed my proposal, my academic work, framework, my results, and recommendations for future proposed work in the field.", develop a tree of concepts of theoretical contributions as mentioned in "I went over all the main points in the dissertation and prepared an outline that also included charts, for example, detailing my innovations and contributions to the field chapter by chapter and then also for the theoretical mainframe ibuilt a tree of concepts with my main theoretical contributions at the core, even if they were just disputing accepted views in the field, so giving it more of a critical weighting or expanding it into new scenarios and considerations. I also tried to incorporate all of the feedback that $i$ had received from committee members at that time, even though i only had this feedback from 3 out of the 5 committee members.", or think about future research directions.

The category of preparing answering questions contains mostly mentions of practicing responses to answering potential questions as mentioned in "Reading my dissertation, coming up with own questions, revisiting referee reports from individual articles, devising answers to written comments of some committee members", as well as practicing questions with the Chair (see: "I did the research and wrote the dissertation. The night before the defense I met with my committee chair and answered questions.") or colleagues, and preparing answers to questions directly based on the assessment of the committee members. 
The committee category includes all mentions that focus on the role of the committee: gather information about committee members (for example: "Read own thesis, one meeting with one supervisor, get idea of committee members"), incorporate committee feedback in the thesis and respond to committee comments on the thesis, meet with committee members, observe committees, read articles by committee members as mentioned in "I read some recent research of my discipline, read recent articles by the committee members and reread my thesis and wrote small summaries about them through Twitter threads", go through the committee reports, and submitting the thesis to the committee as mentioned in "I had to prepare abstracts for all committee members and two complete thesis for the opponents. I provided six review[s] of my thesis from people working in my area."

The role of colleagues, professors, and the supervisor is reflected by mentions of getting advice and feedback from these groups of people, as well as having discussions with them. The answers that mention this category are, for example: "Rehearsal, feedback, improvement, rehearsal. Watching other defenses. Asking advice to my mentors and colleagues, presenting to specific and general audience" and "Made presentation, showed supervisor who gave feedback, meeting with supervisor who told me what to expect, and how to deal with different types of typical questions, practiced presentation in front of some friends, looked through defense clothes with a friend".

In the category of practical issues, we find mentions of preparing the technology for the defense such as "My presentation required some high tech for that time because I introduced short videos with frog calls. For that, a colleague friend of mine helped me. The rest it was on my own" and "made presentation, had a practice defence with colleagues two days before, had to set up a webcam situation in a part of my flat that looked nice, made sure my mobile hotspot was working because my home internet is garbage", making sure there is food or snacks for the attendees, organizing the schedule, booking the room, identifying the clothes for the defense, resting in advance as mentioned in "I prepared normally just as I would for any normal presentation, namely, compiled a nice powerpoint presentation, went over my thesis results, and made sure i had enough sleep before the defense.", relaxation exercises, sports, spiritual practices as mentioned in "I prayed a lot.... and practiced during 5 days before the day", developing a cheat sheet about the protocol during the defense, and reviewing the defense proceedings.

In the category of writing the thesis, we find mentions of doing the research during the years of the PhD and writing the thesis. In many cases, mentions of writing the thesis are considered a first step of multiple actions the respondent undertook towards the defense, as for example in: "Wrote the dissertation, prepared the 30-45 minute oral presentation, reviewed my notes/feedback from advisors". Others indicated that writing the dissertation itself is the most important step in preparing for the defense, as for example: "I wrote and studied my dissertation" and "The defense occurs shortly after the "draft" of the written part of the thesis. Writing the thesis was sufficient for preparation".

Those who focused on highlighting the main contribution focused on emphasizing the main novel findings of the work and summarizing the findings as mentioned in " $I$ prepared [a] summary of my findings to review with the committee. We had the option of a formal powerpoint or verbal presentation before the $Q \mathcal{E} A$ which took the majority of time.", as well as analyzing the strengths and weaknesses of the thesis as highlighted in "I just read and reread the dissertation with my own critical eye, ready for where my analysis may be thin or lacking.".

Those who mentioned previous publications either felt confident in their thesis because some work had already been published as mentioned in "Two papers were submitted for a journal, both were accepted, after that there were a formal defense, were i present bout papers.", or felt confident in their speaking as they had practiced at conferences, or prepared for the defense by revisiting previous publications, comments from reviewers on these publications as mentioned in "Reading my dissertation, coming up with own questions, revisiting referee reports from individual articles, devising answers to written comments of some committee members", or by revisiting their research proposal. 
The category of those who mentioned they attended defenses in preparation only contains mentions of this topic, as for example "Mock defense, re-reading thesis, attend other defenses".

For the parent category of "nothing special" there is one respondent who did not do any special preparation: "In my case, I don't know other candidates even in my department at that time, most of results had already disseminated several time in the form of conference presentations and peer-review journals. There was no special actions for the final defense. But I had done hard exercises for fluent speech.", one who did not prepare at all, and one who prepared as if it were a regular lab meeting ("As regular lab meeting preparation at home").

Table 4. Overview of parent categories from inductive thematic analysis of answers to question "How did you prepare for your defense? Please summarize the actions you undertook to prepare for your defense." Total number of counts $=385$

\begin{tabular}{ccc}
\hline Parent topic & $\%$ & Count \\
\hline Presentation & $20.8 \%$ & 80 \\
Read thesis & $19.2 \%$ & 74 \\
Practicing & $13.8 \%$ & 53 \\
Prepare answering questions & $9.9 \%$ & 38 \\
Research actions & $8.8 \%$ & 34 \\
Committee & $7.3 \%$ & 28 \\
Colleagues, professors, advisor & $4.9 \%$ & 19 \\
Practical issues & $4.2 \%$ & 16 \\
Write thesis & $3.4 \%$ & 13 \\
Highlight main contribution & $1.8 \%$ & 7 \\
Previous publications & $1.6 \%$ & 6 \\
Attend defenses & $1.0 \%$ & 4 \\
Nothing special & $0.8 \%$ & 3 \\
Propositions & $0.8 \%$ & 3 \\
Random & $0.8 \%$ & 3 \\
Blogs and internet & $0.5 \%$ & 2 \\
Prepare speaking & $0.5 \%$ & 2 \\
\hline
\end{tabular}

Three respondents also mentioned the propositions as a step in the preparation: finding the propositions or thinking about how to defend the propositions, for example "Read the various papers published from my research and prepared to defend my prepositions".

The category "random" includes a response that is 5, a respondent indicating they did not know any of the other candidates in the department, and a respondent indicating that it took a month of preparation time.

The category of blogs and internet contains those who read about others' experiences with the defense in blogs (for example "Re read my thesis and committee member comments. Read over blogs etc. of other's defence. Practiced relaxation meditations.") and those who watched YouTube videos.

Finally, the category of "prepare speaking" included a mention of preparing for the defense by giving a another lecture at the research institute (for example: "Presentation to the members of my lab and another talk to the research institute"), and a mention of practicing exercises to be a more fluent speaker.

Another open-ended question that addressed the preparation for the defense is the final question of the survey: "In hindsight, would you have prepared differently for the defense? Describe what you would have done differently." This question received 138 responses, and I used inductive thematic analysis on the answers by first tagging the responses, revising the tags with the memo notes, developing parent categories, and then 
reviewing once more the parent categories. These parent categories are reported in Table 5.

In the parent category "nothing different", the majority of respondents identified that they would have done nothing differently. Others indicated that the defense is difficult to anticipate or that the experience depends on the committee as reflected by "No, in the UK is very much driven by the examiners so the experience can vary quite a lot depending on whom you get as examiner, whether is from the supervisor's academic circle, etc so it is difficult to anticipate", and for that reason they would not have prepared differently, whereas other respondents indicated that they would not have prepared differently because it went well, because it felt easy thanks to good preparation, because the practicing helped, or because job interviews prepared the candidate.

Those who identified that in hindsight they would have benefited from more preparation indicated that they wished they had attended more defenses, or had had more time to prepare as highlighted by "I would have liked more time to prepare, to have a more slick presentation, I kinda felt I winged it, but I had started a postdoc (which I did not enjoy). The organizational side if it (getting the committee together) was also terribly stressful but I don't know what I could have done differently, I wish others had been more cooperating, especially the department:)", had more time to implement the changes to the thesis, had practiced more, or had practiced more responding to potential questions, or had read more (the thesis, papers, or about practical applications of the research) as highlighted by "Read through my thesis in more detail and had more questions asked during the research process by people in a different subject area", or reflected more on the connection with other works.

Those who would have gone in with a different mindset mentioned the following: be more confident as identified by "Be less nervous, trust more in myself, in what I think and what I have done", breathe more, relax more and stress less as highlighted by "Would have been more confident about myself and less stressed; Would have not tried to make it approachable for non scientific people as well as my guest did not get it anyway...", take better care of their health, or treat it more like a job interview as explained by "I would have been more formal (suit and tie) and practice giving confident answers. I would have treated it more like a job interview where you need to 'impress'; so style/salesmanship would have played more a role."

Some respondents highlighted that their defense was a positive experience, indicating that they enjoyed: "Honestly, I would not. I surprised myself by how much in control I was and received a lot of praise for the elegance, clarity and accessibility of my talk. Overall, I felt that I was ready and despite the stress I truly enjoyed the chance to discuss my work with the public and the members of my committee.", felt confident, felt proud, felt that their advisor prepared them well, that reading how-to guides helped, or that positive committee interaction helped feeling more confident as indicated by "I would have breathed more and felt more confident in my work. To be fair I received a very thoughtful wonderful appraisal by my external examiner beforehand and thus felt more confident."

Those who would have presented their work differently mentioned the following changes they would have made in hindsight: not attempt to adjust the presentation for a broader audience, focus more on the global aspects of the research rather than the details, focus on different topics, keep better track of time during the presentation as mentioned "Maybe keep better track of the time it would take me to deliver the presentation... at the end I was rushing and that had an effect on it", use less slides, spend less time on the summary and more on general questions, highlight the novel findings more, or have a shorter presentation.

For those who mentioned they would have had a different committee interaction, I identified the following topics: consult with other committee members before the defense as highlighted by "My advisor/supervisor who was also committee chair did very little to prepare me. I would have consulted with other committee members before the defense.", have different committee members, or more gender balance in the committee, insist on receiving feedback in advance and prepare for negative comments as illustrated in "I would have insisted on having feedback from all of the committee members before the defense so there wouldn't be any 
surprises. I could have prepared better in advance if I had known all the criticism before, particularly the negative comments".

Those who mentioned a lack of support identified that their supervisor did not prepare them well, that they would have liked better guidance from their university or department as mentioned by "I would have appreciated departmental support - which was virtually nonexistent. Then again, support was thin on the ground for my PhD as a whole.", or that they wished they would have been able to go to conferences as identified by "Yes, I was external PhD, not paid by uni, but by ngo. I attended very few defenses, did no sessions on conferences presenting my work. I would do that different. And did not do an exercise defense with uni colleagues".

In the category of practical issues there are mentions of potentially considering audio-visual products as defense products, having an emergency plan for the technology during the defense as highlighted in "The streaming failed on the part of the university, so none of my guests were able to see the opening presentation until my paranymphs called the university to tell them it wasn't working. In retrospect, I would have made an emergency plan for if the streaming doesn't work, as my friends in the flat could have come and told me during the presentation and it could have been sorted.", have less bureaucracy, wear more formal clothing, and schedule more in advance.

The respondents who highlighted research and writing issues identified issues that happened during the $\mathrm{PhD}$ years that ultimately influenced the defense, such as wishing they had found a flaw in the data analysis so that the thesis revisions would have been more moderate, changed the overall approach of the $\mathrm{PhD}$ as for example "I would have changed my approach to the development of the thesis and my expectations on my advisor", get feedback from others during the PhD years, or have publications.

The mentions in the parent category "mock defense" either included those who did not have a mock defense at all, or those who wish their mock defense more in line with a regular defense, as exemplified in this quote: "There were some questions which I never thought committee members would ask. I wish I had more experienced people while giving a mock presentation."

Those who would have appreciated more feedback before the defense particularly mentioned they would have benefited from more feedback from their peers (for example: "tried harder to practice on peer PhD students") or from their supervisor.

Those who had a negative experience during the defense include those who received a negative outcome unexpectedly, for example: "I don't think I could have - I had had no reason to believe I would be asked to revise and resubmit until I was actually there.", those who would prefer the abolition of the oral defense, as explained by: "I wouldn't have prepared differently. I wish the oral presentation were eliminated. It is over-emphasized in the US and doesn't serve a real purpose.", a respondent who would have changed "Everything from the beginning", and a respondent who flagged committee misconduct.

The respondents who would have prepared less mentioned that they would have read their thesis not so many times or rehearsed less, as illustrated for example by: "I think I was over-rehearsed and didn't sound quite as natural".

Finally, those who mentioned that the defense would be different nowadays include a respondent who did not have an oral defense but only a written rebuttal instead as highlighted by "I only had minor corrections, and so only had to write a response to examiners; despite that, I found myself wishing to have an oral defense as I felt it would have been easier to demonstrate my abilities in that type of forum (recognizing, of course, that it was in my first language, and I have years or public speaking experience, including at conferences having published from my Masters and during my PhD). I imagine that people in different circumstances may prefer to the written bases response for minor reflections.", as well as a respondent who would have had more options today as explained: "I'm not sure what I could have done differently at the time. If I were doing a PhD today I would have many more options.". 
Table 5. Overview of parent categories from inductive thematic analysis of answers to question "In hindsight, would you have prepared differently for the defense? Describe what you would have done differently." Total number of counts $=168$.

\begin{tabular}{ccc}
\hline Parent topic & $\%$ & Count \\
\hline Nothing different & $47.6 \%$ & 80 \\
More preparation & $11.9 \%$ & 20 \\
Different mindset & $6.0 \%$ & 10 \\
Present contents differently & $5.4 \%$ & 9 \\
Positive experience & $4.8 \%$ & 8 \\
Different committee interaction & $4.2 \%$ & 7 \\
Lack of support & $3.6 \%$ & 6 \\
Practical issues & $3.6 \%$ & 6 \\
Mock defense & $3.0 \%$ & 5 \\
Research and writing issues & $3.0 \%$ & 5 \\
Negative experience & $2.4 \%$ & 4 \\
Less preparation & $1.8 \%$ & 3 \\
More feedback & $1.8 \%$ & 3 \\
Defense would be different today & $1.2 \%$ & 2 \\
\hline
\end{tabular}

\subsection{Association between defense preparation and defense}

\subsubsection{Association between defense preparation and defense outcome}

In this section, I explore the association between defense preparation (mock defense, preparation course, and preparatory reading) and the defense outcome in terms of decisions and overall length of the defense.

There is no statistically significant relation between the defense outcome and the mock defense. A potential reason for the lack of relation may be the low number of respondents in the survey who received major corrections. Breaking down the outcome of the defense by the type of practice prior to the defense, as shown in Table 6, we can see differences in the percentage of respondents who received major corrections as a function of the type of practice. In particular, the respondents who had a mock defense had a lower percentage $(1.5 \%)$ of major corrections as the outcome as compared to those who had another type of practice ( $4.2 \%$ with major corrections) and no practice ( $4.7 \%$ with major corrections). However, drawing conclusions about the influence of having a mock defense or not on the outcome of the defense would be preliminary, as only 7 respondents in this analysis received major corrections.

Similarly, there is no statistically significant relation between having a mock defense or not, and the duration of the defense. However, when breaking down the results of the length of the defense by type of practice, I observe differences in terms of the relatively short and rather long defense, see Table 7. For example, more respondents of those who had a mock defense $(17.9 \%$ ) had a defense of less than one hour than those who had another type of practice $(10.6 \%)$ or no practice at all $(8.1 \%)$. Reversely, less participants who had a mock defense had a defense of over three hours $(3.0 \%)$ as compared to those who had another type of practice $(6.4 \%)$ and no practice $(5.8 \%)$. This observation could potentially mean that those who are well prepared through a mock defense are 'let off the hook' more quickly than those who did not practice the defense, and that those who did not practice the defense, are more often being 'grilled' with questions, resulting in slightly more defenses of over three hours. These explanations are, however, rather preliminary, and would require more data on particularly short and long defenses.

Table 6. Breakdown of defense outcome by type of practice prior to the defense. $n=202$.

Mock defense Other type of practice No practice 


\begin{tabular}{cccc}
\hline Passed & $66.2 \%$ & $70.8 \%$ & $68.6 \%$ \\
Minor corrections & $32.4 \%$ & $25.0 \%$ & $26.7 \%$ \\
Major corrections & $1.5 \%$ & $4.2 \%$ & $4.7 \%$ \\
\hline
\end{tabular}

Table 7. Breakdown of length of defense by type of practice prior to the defense. $n=200$.

\begin{tabular}{cccc}
\hline & Mock defense & Other type of practice & No practice \\
\hline Less than 1 hour & $17.9 \%$ & $10.6 \%$ & $8.1 \%$ \\
1 hour - 1.5 hours & $25.4 \%$ & $21.3 \%$ & $31.4 \%$ \\
1.5 hours - 2 hours & $29.9 \%$ & $36.2 \%$ & $37.2 \%$ \\
2 hours - 3 hours & $23.9 \%$ & $25.5 \%$ & $17.4 \%$ \\
More than 3 hours & $3.0 \%$ & $6.4 \%$ & $5.8 \%$ \\
\hline
\end{tabular}

Comparing the influence of having a course to prepare for the defense, there is a statistically significant relation between the outcome and the categories related to having a course ( $p=8.5 \times 10^{-5}$ using a Kruskal-Wallis test for the three categories). However, recoding the results into the groups of those who participated in a course (grouping those who had a course about the defense and those who had the course as part of a general PhD course) and those who did not have a course, and using a Wilcoxon rank sum test showed no statistically significant relation. Table 8 shows the breakdown of outcomes of the defense by type of course. From this table, we can observe that there is a large difference in results between those $(n=11)$ who took a course to prepare for the defense, and those $(n=6)$ who had it as part of another $\mathrm{PhD}$ course. The group of which the largest percentage passed directly, is those who had the course about the defense as part of another PhD course, and none of the respondents in this group received major corrections. Reversely, of those who took a course about the defense, only $9.1 \%$ passed directly, and the largest percentage of respondents among the different course categories $(9.1 \%)$ received major corrections. Before trying to find an explanation for these results, it is important to point out the low number of respondents in the categories of those who prepared with a course $(n=11$ with a course about the defense, and $n=6$ as part of another PhD course, as compared to $n=185$ who had no preparation course). A potential explanation is that those who took a course about the defense were located in a country where major revisions are more likely to be the outcome of the defense as a result of the defense format. Indeed, looking at the breakdown of the groups of defense courses by country of defense, Table 9 shows that a larger percentage in the UK took a course about the defense itself. As such, we can explain the larger frequency of major corrections for those who took a course about the defense.

There is no statistically significant relation between the categories of courses and the duration of the defense. Looking at the results in Table 10, we can observe that those who took a course about the defense itself had the largest percentage $(9.1 \%)$ of respondents with a defense of more than 3 hours, whereas those who prepared for the defense as part of another PhD course had the largest percentage (50\%) of those whose defense took less than 1 hour. Again, the link to the country of defense and the defense format (see Table 9) can explain the differences here. In conclusion, it is not so much the action of taking the course that influences the defense outcome and duration, but taking courses is related to the country where the doctoral candidate studied, and thus to the defense format.

Table 8. Breakdown of defense outcome by categories of preparation courses. $n=202$.

\begin{tabular}{cccc}
\hline & $\begin{array}{c}\text { Course about } \\
\text { the defense }\end{array}$ & $\begin{array}{c}\text { Part of another } \\
\text { PhD course }\end{array}$ & No \\
\hline Passed & $9.1 \%$ & $83.3 \%$ & $71.4 \%$ \\
Minor corrections & $81.8 \%$ & $16.7 \%$ & $25.4 \%$ \\
\hline
\end{tabular}




\begin{tabular}{llll}
\hline Major corrections & $9.1 \%$ & $0.0 \%$ & $3.2 \%$ \\
\hline
\end{tabular}

Table 9. Breakdown of categories of preparation courses by country of PhD defense, showing only the results from the countries that were most frequently selected. Note that the data in the columns of course categories show the breakdown of the responses per country.

\begin{tabular}{ccccc}
\hline & $\boldsymbol{n}$ & $\begin{array}{c}\text { Course about } \\
\text { the defense }\end{array}$ & $\begin{array}{c}\text { Part of another } \\
\text { PhD course }\end{array}$ & No \\
\hline Belgium & 5 & $0.0 \%$ & $0.0 \%$ & $100.0 \%$ \\
Canada & 18 & $5.6 \%$ & $0.0 \%$ & $94.4 \%$ \\
France & 6 & $16.7 \%$ & $0.0 \%$ & $83.3 \%$ \\
Netherlands & 32 & $0.0 \%$ & $0.0 \%$ & $100.0 \%$ \\
Spain & 6 & $0.0 \%$ & $0.0 \%$ & $100.0 \%$ \\
United Kingdom & 24 & $20.8 \%$ & $4.2 \%$ & $75.0 \%$ \\
United States of America & 66 & $0.0 \%$ & $6.1 \%$ & $93.9 \%$ \\
\hline
\end{tabular}

Table 10. Breakdown of length of defense by categories of preparation courses. $n=200$.

\begin{tabular}{cccc}
\hline & $\begin{array}{c}\text { Course about } \\
\text { the defense }\end{array}$ & $\begin{array}{c}\text { Part of another } \\
\text { PhD course }\end{array}$ & No \\
\hline Less than 1 hour & $0.0 \%$ & $50.0 \%$ & $11.5 \%$ \\
1 hour - 1.5 hours & $18.2 \%$ & $16.7 \%$ & $27.9 \%$ \\
1.5 hours - 2 hours & $54.6 \%$ & $16.7 \%$ & $33.9 \%$ \\
2 hours - 3 hours & $18.2 \%$ & $16.7 \%$ & $21.9 \%$ \\
More than 3 hours & $9.1 \%$ & $0.0 \%$ & $4.9 \%$ \\
\hline
\end{tabular}

There is a statistically significant relation between preparing for the defense by reading and the outcome of the defense ( $p=9.87 \times 10^{-4}$ using a Wilcoxon rank sum test). Surprisingly, however, the results (Table 11) show that a larger percentage of those who did not read about the defense as part of their preparation $(74.4 \%)$ passed than those who did read $(47.8 \%)$. However, this observation can be linked again to the defense format and country (Table 12), and we see that in the UK, where corrections are more common because of the defense format, reading about the defense is more common than in other countries. There is no statistically significant correlation between preparatory reading and the length of the defense. The results in Table 13 show that overall the length of the defense is distributed among the different categories of length in the same way for those who did preparatory reading as for those who did not.

Table 11. Breakdown of outcome of defense by preparatory reading or not. $n=200$.

\begin{tabular}{ccc}
\hline & Yes & No \\
\hline Passed & $47.8 \%$ & $74.4 \%$ \\
Minor corrections & $47.8 \%$ & $22.4 \%$ \\
Major corrections & $4.4 \%$ & $3.2 \%$ \\
\hline
\end{tabular}

Table 12. Breakdown of preparatory reading or not by country of defense. Note that the data in the columns of reading categories show the breakdown of the responses per country.

\begin{tabular}{cccc}
\hline & $\boldsymbol{n}$ & Yes & No \\
\hline Belgium & 5 & $20.0 \%$ & $80.0 \%$ \\
\hline
\end{tabular}




\begin{tabular}{cccc}
\hline Canada & 18 & $16.7 \%$ & $83.3 \%$ \\
France & 6 & $16.7 \%$ & $83.3 \%$ \\
Netherlands & 32 & $21.9 \%$ & $78.1 \%$ \\
Spain & 6 & $16.7 \%$ & $83.3 \%$ \\
United Kingdom & 24 & $45.8 \%$ & $54.2 \%$ \\
United States of America & 66 & $13.6 \%$ & $86.4 \%$ \\
\hline
\end{tabular}

Table 13. Breakdown of preparatory reading or not by length of defense. $n=200$.

\begin{tabular}{ccc}
\hline & Yes & No \\
\hline Less than 1 hour & $13.3 \%$ & $11.6 \%$ \\
1 hour - 1.5 hours & $15.6 \%$ & $30.3 \%$ \\
1.5 hours - 2 hours & $48.9 \%$ & $30.3 \%$ \\
2 hours - 3 hours & $20.0 \%$ & $21.9 \%$ \\
More than 3 hours & $2.2 \%$ & $5.8 \%$ \\
\hline
\end{tabular}

\subsubsection{Association between mock defense and perception}

In this section, the relation between the aspects of defense preparation and students' perception of the doctoral defense are analyzed, based on the analysis matrix from Table 1.

First, the relation between having a mock defense, another type of practice, or no practice with perception of the doctoral defense is studied. There is no statistically significant relation between nervousness before and during the defense. Looking at the results in Figure 1, however, we do see some differences across the categories. For the sentiment of nervousness before the defense, there are no markable differences across the categories of practice before the defense. For the sentiment of nervousness during the defense, the mean values are different in the categories of practice: the mean value on a 0-10 Likert scale of nervousness (from not nervous at all to extremely nervous) is 4.52 for those who did a mock defense, 5.10 for those with a difference practice, and 4.94 for those with no practice at all. There is a statistically significant relation $(p=0.041)$ between nervousness after the defense and before receiving the outcome, and type of practice for the defense. The mean value is 3.22 for those who had a mock defense, 4.31 for those with a different type of practice, and 4.48 for those who did not have any practice in advance. In terms of nervousness, there are thus some indications that a mock defense helps mitigating nervousness during the defense and afterwards, while waiting for the outcome.

There is a weak relation $(p=0.068)$ between the enjoyment of the defense and the type of practice. There are differences in mean values on a 0-10 scale of enjoyment, with 0 equal to "not at all" and $10=$ "enjoyed it very much" for categories of practice. Those who had a mock defense have a mean enjoyment of 7.22, those who had some other form of practice 6.55, and those who had no practice 6.20, as can be seen on Figure 2a. It seems that those with a mock defense enjoyed the defense more.

For the perceived importance of the defense, there is no statistical significance in the relation to the type of practice before the defense. There are however some differences in terms of median values across the categories: the median is 8 for those who had a mock defense, 7.5 for those who had other practice, and 9 for those who did not have practice. As such, there are some indications that the defense is perceived as more important by those who did not get to practice the defense in advance, as can also be seen in Figure $2 b$. These results indicate that those who had practice in advance felt the importance a bit less than those who had no practice. 

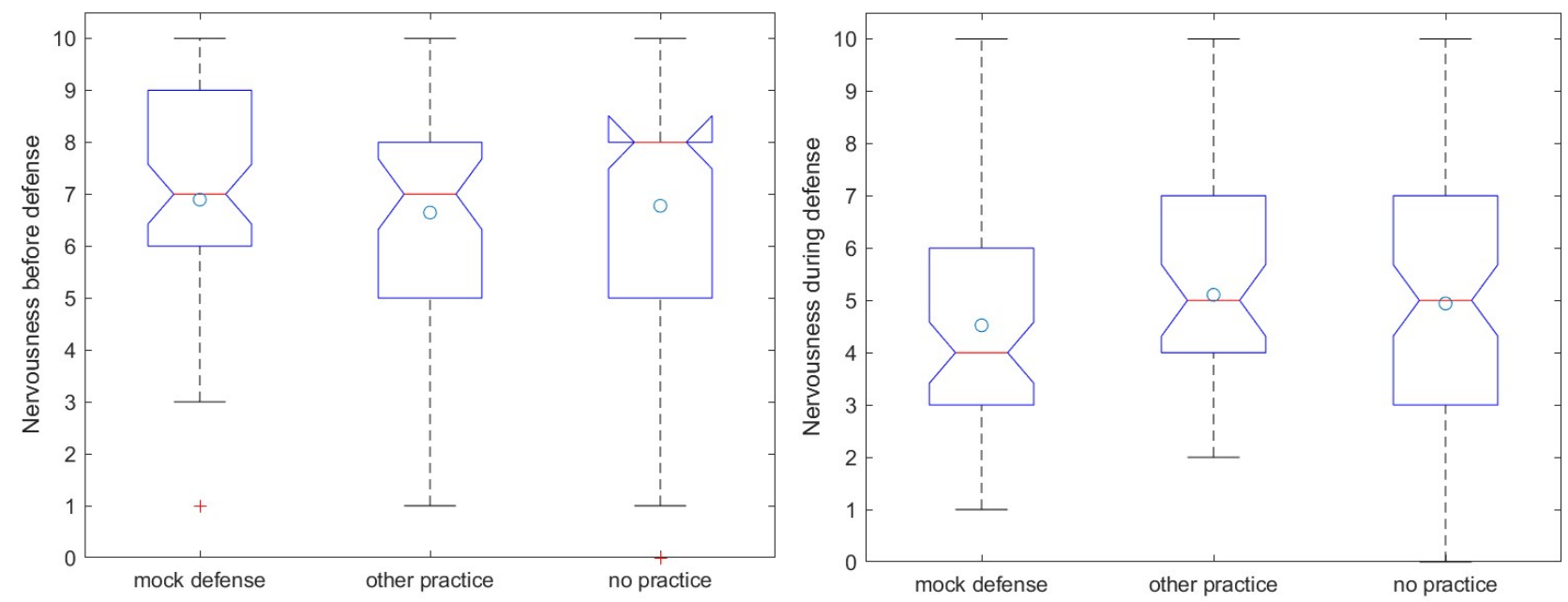

(a)

(b)

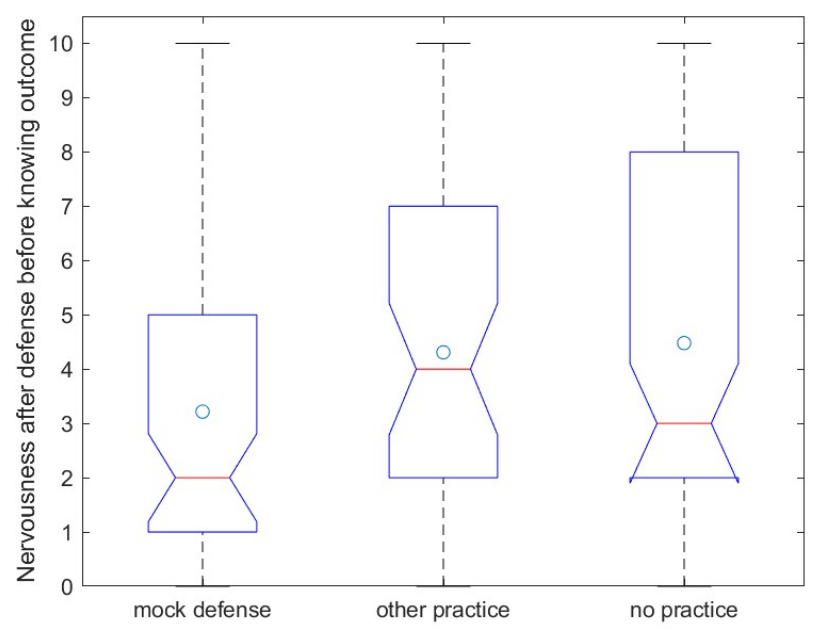

(c)

Figure 1. Influence of type of practice before the defense on nervousness (a) before the defense, (b) during the defense, (c) after the defense and before receiving the outcome. $n=202$

In terms of perceived difficulty of the defense in relation to practice before the defense, there is no statistical relation between the categories. There are some differences in mean value of difficulty on a scale from 0 (extremely easy) to 10 (extremely difficult): 5.84 for those with a mock defense, 5.64 for those with another type of practice, and 6.08 for those who did not have practice before the defense, as can also be seen in Figure 2c. From these results, we see some indication that those who had practiced before the defense find it slightly less difficult than those who did not practice. 

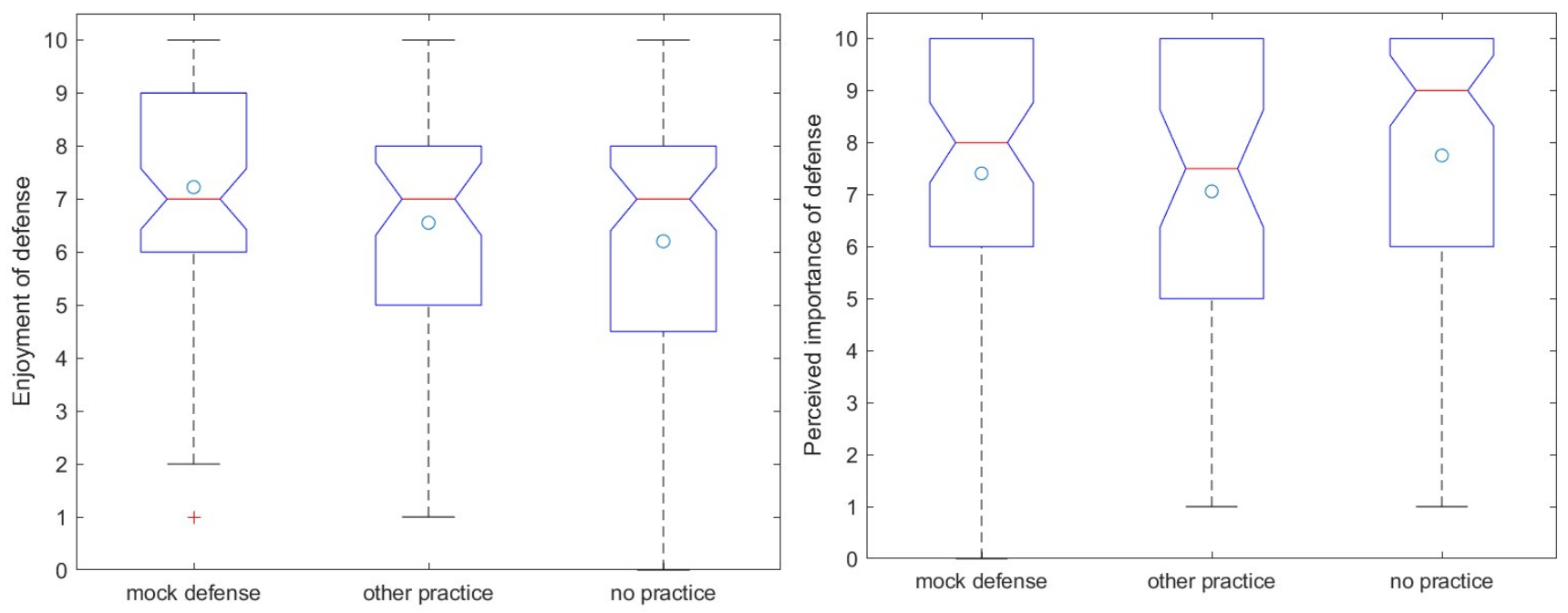

(a)

(b)
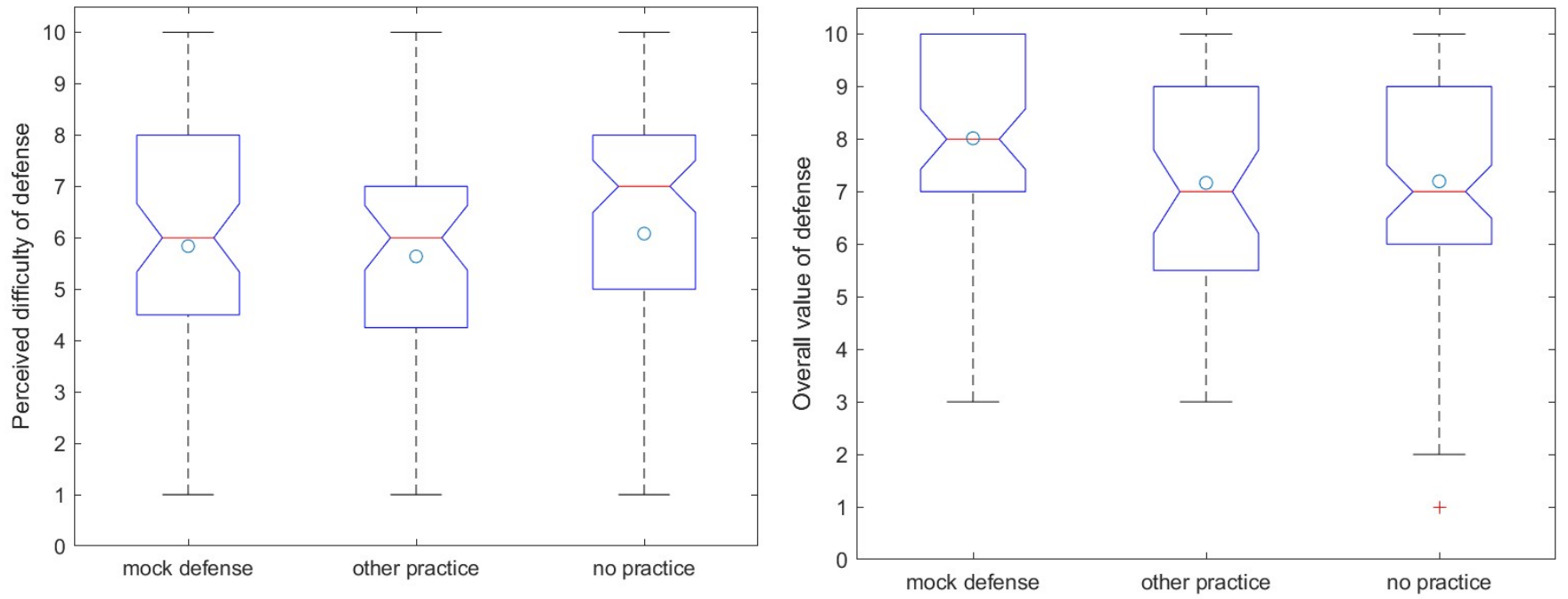

(c)

(d)

Figure 2. Influence of type of practice before the defense on (a) enjoyment of the defense, (b) perceived importance of the defense, (c) perceived difficulty of defense, (d) overall value of the defense. $n=202$

There is a statistical relation $(p=0.051)$ between the overall value of the defense and the type of practice before the defense, and the categories are plotted in Figure $2 \mathrm{~d}$. This observation is also reflected by the differences in mean values of overall value on a scale from 0 (not worth at all) to 10 (extremely valuable experience) by categories of practice: the mean value is 8.01 for those who had a mock defense, 7.17 for those with a different form of practice, and 7.20 for those with no practice at all. As such, we can observe that the mock defense has a positive impact on the perceived value of the defense. 
In terms of the relation between the type of practice and committee fairness and suitability, we can observe differences across the categories, as shown in Table 14. For those who had a mock defense, a larger percentage of respondents $(91.0 \%)$ considered their committee fair than for those who had another form of practice $(87.5 \%)$ or no practice (76.5\%). Similarly, we can observe in Table 14 a link between committee suitability and the categories of practice before the defense. A larger percentage of respondents who had a mock defense $(82.4 \%)$ considered their committee suitable than those who had another form of practice $(77.1 \%)$ or no practice $(79.1 \%)$. Combining the observations on committee fairness and suitability, we see for both categories a positive effect for those who had a mock defense. While it's not likely that the mock defense itself changes the behavior of committee members, I suspect that there is a link between the good practice of having a mock defense and having good practices in place in terms of committee selection. A potential source of this link could be an involved supervisor, who dedicates time to the preparation of their doctoral candidates prior to the defense, and who is careful in selecting or suggesting committee members.

When it comes to the perceived purpose of the defense, there are no differences when the results are broken down by the different categories of practice before the defense, see Table 15.

Table 14. Committee fairness and suitability, by type of practice before the defense.

\begin{tabular}{cccc}
\hline & Mock defense & Other practice & No practice \\
\hline & Did you consider your committee fair? & \\
Yes & $n=67$ & $n=48$ & $n=85$ \\
To some extent & $91.0 \%$ & $87.5 \%$ & $76.5 \%$ \\
No & $9.0 \%$ & $10.4 \%$ & $22.4 \%$ \\
Did you consider your committee suitable for making & a well-balanced assessment of your work? \\
& $0.0 \%$ & $n=48$ & $n=86$ \\
Yes & $n=68$ & $77.1 \%$ & $79.1 \%$ \\
To some extent & $82.4 \%$ & $20.8 \%$ & $18.6 \%$ \\
No & $17.7 \%$ & $2.1 \%$ & $2.3 \%$ \\
\hline
\end{tabular}

Table 15. Perceived purpose of the defense, by type of practice before the defense. Participants were asked to check all that apply, so reported values of $n$ are the number of responses of all checked answers together, not the individual respondents.

\begin{tabular}{cccc}
\hline & $\begin{array}{c}\text { Mock defense } \\
n=179\end{array}$ & $\begin{array}{c}\text { Other type of practice } \\
n=139\end{array}$ & $\begin{array}{c}\text { No practice } \\
n=218\end{array}$ \\
\hline Examination & $30.2 \%$ & $25.9 \%$ & $31.2 \%$ \\
Ceremony & $17.9 \%$ & $17.3 \%$ & $13.3 \%$ \\
Celebration & $14.0 \%$ & $14.4 \%$ & $11.0 \%$ \\
Confirmation & $19.0 \%$ & $20.9 \%$ & $19.3 \%$ \\
Rite of passage & $19.0 \%$ & $16.6 \%$ & $22.0 \%$ \\
Other & $0.0 \%$ & $5.0 \%$ & $3.2 \%$ \\
\hline
\end{tabular}

When it comes to the long-term impact of the defense on student perception in relation to the type of practice, we can observe marked differences between those who had some form of practice (mock defense or other) and those who did not have a practice in advance, see Table 16 . In particular, a larger percentage of those who had practice $(60.3 \%$ for those with a mock defense and $68.8 \%$ for those with other practice) felt that the defense increased their perception of their academic competence than for those who did not have practice $(47.7 \%)$. Similarly, a larger percentage of respondents who practiced (35.3\% of those who had a mock defense and $35.4 \%$ of those who had other practice) report that the 
defense increased their desire to continue to work in the sphere of their PhD research than those who did not have practice $(26.7 \%)$. A larger percentage of respondents who practiced $(33.8 \%$ of those who had a mock defense and $35.4 \%$ of those with other practice) perceived that the defense increased their desire to work in academia, as compared to those who did not practice (19.8\%). Finally, a larger percentage of those who practiced ( $44.1 \%$ of those with a mock defense and $43.8 \%$ of those without practice) perceived that the defense increased their perceived publishability of their research, as compared to those who did not practice $(31.4 \%)$.

Table 16. Long-term impact of defense on student perception, by type of practice before the defense.

\begin{tabular}{|c|c|c|c|}
\hline & Mock defense & Other practice & No practice \\
\hline \multicolumn{4}{|c|}{ How did your defense influence your perception of your academic competence? } \\
\hline & $n=68$ & $n=48$ & $n=86$ \\
\hline Increased & $60.3 \%$ & $68.8 \%$ & $47.7 \%$ \\
\hline Not affected & $33.8 \%$ & $31.3 \%$ & $36.1 \%$ \\
\hline Decreased & $5.9 \%$ & $0.0 \%$ & $16.3 \%$ \\
\hline \multicolumn{4}{|c|}{ How did your defense influence your desire to continue to work in the sphere of your PhD research } \\
\hline & $n=68$ & $n=48$ & $n=86$ \\
\hline Increased & $35.3 \%$ & $35.4 \%$ & $26.7 \%$ \\
\hline Not affected & $57.4 \%$ & $62.5 \%$ & $61.6 \%$ \\
\hline Decreased & $7.4 \%$ & $2.1 \%$ & $11.6 \%$ \\
\hline \multicolumn{4}{|c|}{ How did your defense influence your desire to work in academia? } \\
\hline & $n=68$ & $n=48$ & $n=86$ \\
\hline Increased & $33.8 \%$ & $35.4 \%$ & $19.8 \%$ \\
\hline Not affected & $55.9 \%$ & $60.4 \%$ & $68.6 \%$ \\
\hline Decreased & $10.3 \%$ & $4.2 \%$ & $11.6 \%$ \\
\hline \multicolumn{4}{|c|}{ How did your defense influence your perception on the publishability of your research? } \\
\hline & $n=68$ & $n=48$ & $n=86$ \\
\hline Increased & $44.1 \%$ & $43.8 \%$ & $31.4 \%$ \\
\hline Not affected & $44.1 \%$ & $54.2 \%$ & $58.1 \%$ \\
\hline Decreased & $11.8 \%$ & $2.1 \%$ & $10.5 \%$ \\
\hline
\end{tabular}

Bringing together the results of the influence of different categories of practice before the defense on the perception of the students, I conclude that having a mock defense has a positive impact on the perception of doctoral candidates during the defense and long term. To better understand the reasons why the mock defense positively impacts the perception, qualitative research on the topic, which also addresses the role of the supervisor, should be carried out in future research. In addition, an intervention study to understand the impact of a mock defense could be recommended.

\subsubsection{Association between preparatory course and perception}

A second aspect to explore with regard to perception of the doctoral defense, is the effect of taking a preparatory course. In terms of nervousness before, during, and after the defense, there is no statistically significant relation with the categories of taking a course. The average values differ between the categories. For nervousness before the defense, the mean value is 7.73 for those who took a course about the defense, 6.33 for those who took it as part of a general PhD course, and 6.74 for those who did not take a course. For nervousness during the defense, the mean value is 5.82 for those who took a defense course, 4 for those who took it as part of a general $\mathrm{PhD}$ course, and 4.81 for those who took no course. Finally, for nervousness after the defense and before receiving the outcome, the mean value is 5 for those who took a PhD defense course, 2.83 for those who took it as part of a general PhD course, and 4.00 for those who did not take a preparatory course. 
From these results, it seems that a course about the PhD defense does not reduce nervousness and even seems to increase it as compared to those who did not take any preparatory course, while those who followed a module as part of a general $\mathrm{PhD}$ course report lower nervousness levels.

There is a statistically significant relation between the categories of preparatory courses and perceived importance of the defense $(p=0.0178)$. Those who took a course about the defense perceived the defense as more important (mean $=9.45$ ) than those who prepared with a general PhD course (mean $=7.50$ ) or those who did not take a course (mean $=7.35$ ), see Figure 3a.

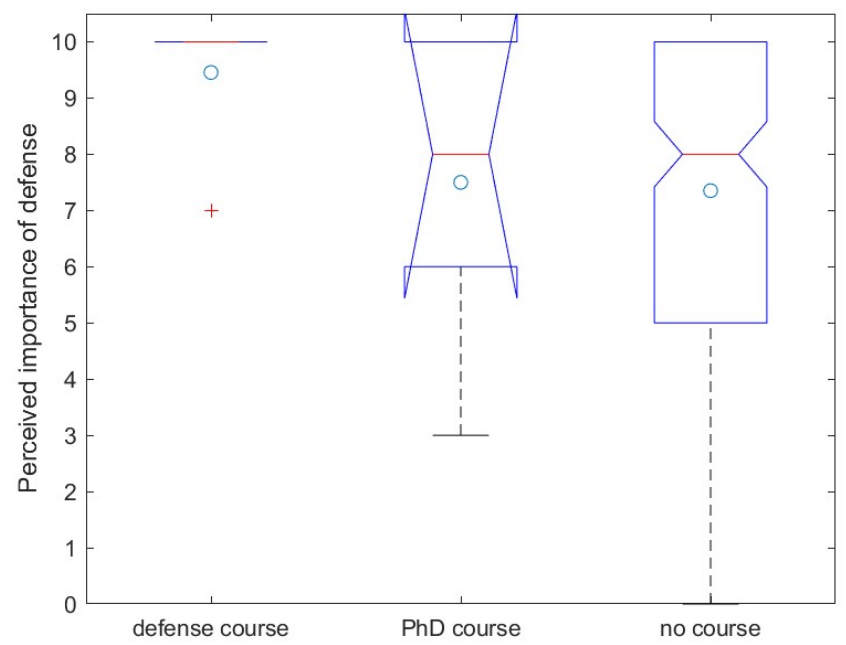

(a)

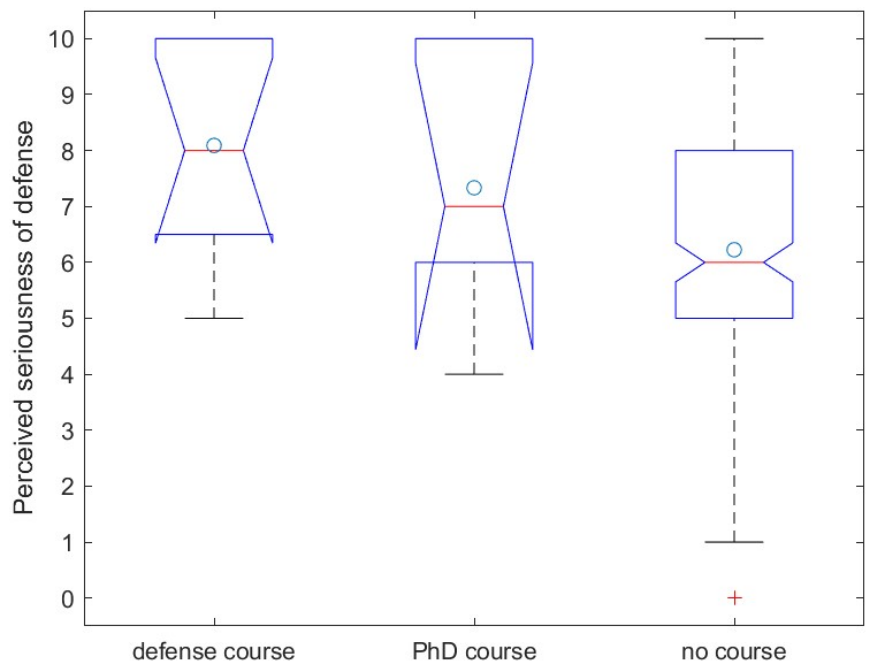

(c)

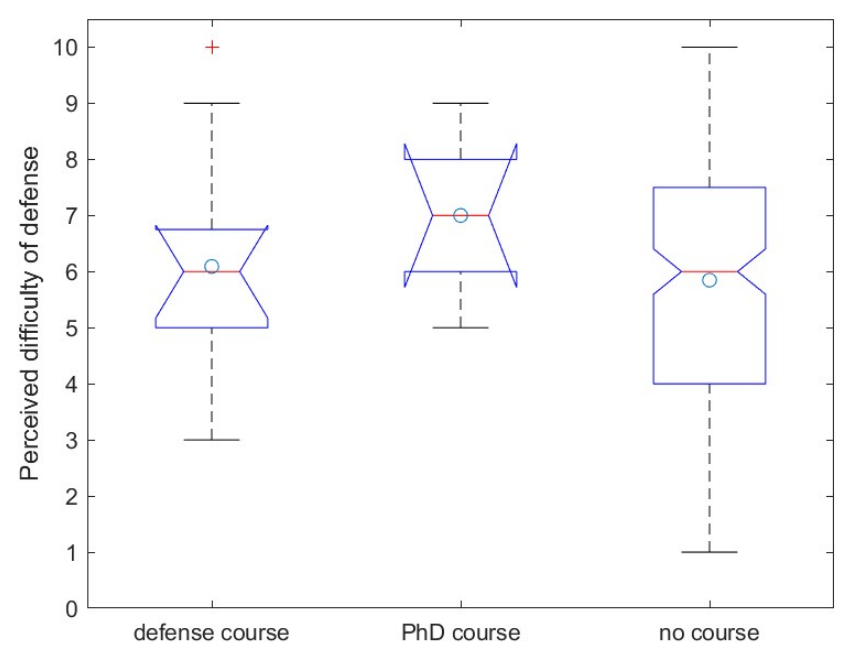

(b)

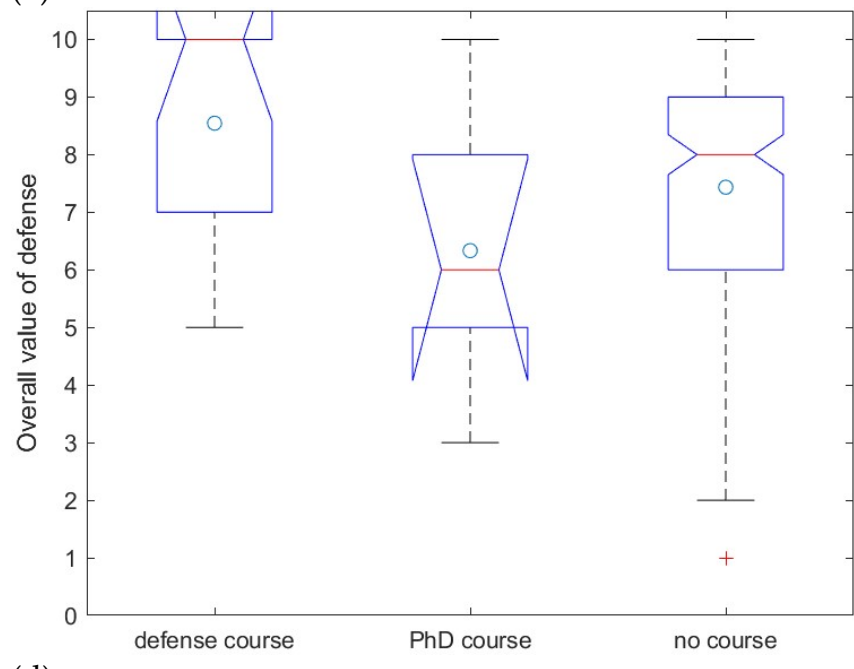

(d)

Figure 3. Influence of type of preparatory course before the defense on (a) perceived importance of the defense, (b) perceived difficulty of the defense, (c) perceived seriousness of the defense proceedings, (d) overall value of the defense. $n=202$

In terms of the perceived difficulty of the defense, there is no statistically significant relation to the type of course taking in preparation. There are some minor difference between the categories, and those who did not prepare with a course perceived the defense on average less difficult (mean $=5.85$ ) than those who prepared with a course $($ mean $=6.09$ for those who took a course about the defense, and mean $=7.0$ for those who took a general PhD course), see Figure $3 b$. 
Those who took a preparatory course for the defense perceived the defense as more serious (mean $=8.09$ for those who took a course about the defense, and mean $=7.33$ for those who took it as part of a general PhD course) than those who did not (mean $=6.23$ ), and this relationship is significant $(p=0.0343)$. This observation is also reflected by the boxplot in Figure 3c.

Those who took a course to prepare for the defense rate the defense as higher (mean $=8.55)$ than those who prepared with a general $\mathrm{PhD}$ course (mean $=6.33$ ) and those who did not take a course (mean $=7.43$ ), see Figure $3 \mathrm{~d}$. The relationship between overall value and the categories of preparatory courses is not statistically relevant.

The results of committee fairness and suitability are broken down by categories of preparatory course before the defense in Table 17. There seems to be no or potentially a small positive influence of a preparation course on committee fairness and suitability.

Table 17. Committee fairness and suitability, by type of preparatory course before the defense.

\begin{tabular}{cccc}
\hline & Defense course & PhD course & no course \\
\hline & Did you consider your committee fair? & \\
Yes & $n=11$ & $n=6$ & $n=183$ \\
To some extent & $90.9 \%$ & $100.0 \%$ & $83.1 \%$ \\
No & $9.1 \%$ & $0.0 \%$ & $15.6 \%$ \\
\hline Did you consider your committee suitable for making & a well-balanced assessment of your work? \\
& $n=11$ & $n=6$ & $n=185$ \\
Yes & $81.8 \%$ & $100.0 \%$ & $78.9 \%$ \\
To some extent & $18.2 \%$ & $0.0 \%$ & $19.5 \%$ \\
No & $0.0 \%$ & $0.0 \%$ & $1.6 \%$ \\
\hline
\end{tabular}

Table 18. Perceived purpose of the defense, by type of preparatory course before the defense. Participants were asked to check all that apply, so reported values of $n$ are the number of responses of all checked answers together, not the individual respondents.

\begin{tabular}{cccc}
\hline & $\begin{array}{c}\text { Defense course } \\
n=25\end{array}$ & $\begin{array}{c}\text { PhD course } \\
n=19\end{array}$ & $\begin{array}{c}\text { no course } \\
n=492\end{array}$ \\
\hline Examination & $44.0 \%$ & $15.8 \%$ & $29.3 \%$ \\
Ceremony & $8.0 \%$ & $21.1 \%$ & $16.1 \%$ \\
Celebration & $12.0 \%$ & $15.8 \%$ & $12.8 \%$ \\
Confirmation & $20.0 \%$ & $26.3 \%$ & $19.3 \%$ \\
Rite of passage & $12.0 \%$ & $21.1 \%$ & $19.9 \%$ \\
Other & $4.0 \%$ & $0.0 \%$ & $2.6 \%$ \\
\hline
\end{tabular}

In terms of the perceived purpose of the defense, Table 18 shows the results broken down by category of preparatory course. Percentagewise more participants who took a course about the defense $(44.0 \%)$ perceived its purpose as that of an examination as compared to those who took it as part of another PhD course $(15.8 \%)$ and those who did not take a preparatory course $(29.3 \%)$. At the same time, percentagewise less participants who took a course about the defense in preparation perceived it as a ceremony $(8.0 \%)$ or rite of of passage $(12.0 \%)$ than those who took it as part of another $\mathrm{PhD}$ course (ceremony $=21.1 \%$ and rite of passage $=21.1 \%$ ) and those who did not take a course (ceremony $=16.1 \%$, rite of passage $=19.9 \%$ ). This observation can be linked to the defense format and country of the defense, with percentagewise more participants from the UK taking a preparatory course. Since in the UK the thesis is finalized only after the defense, and the defense involves committee members who are called examiners, the defense may have felt more like an examination for a relatively larger share of this group of respondents. 
In terms of long-term impact of the defense, the influence of the different categories of preparatory courses shows a mixed picture. Relatively more respondents who took a defense course $(27.3 \%)$ report that the defense decreased the perception of their academic competence than those who took it as part of another PhD course $(0.0 \%)$ or those who did not take a course $(8.1 \%)$. When it comes to the desire to continue to work in the sphere of the PhD research, more participants who took a course about the defense $(45.5 \%)$ report an increase in this desire as compared to those who took it as part of another PhD course $(33.3 \%)$ and those who did not take a preparatory course $(30.8 \%)$. Yet, at the same time, more participants who prepared with a module as part of another PhD course report a decrease in the desire to continue to work in the sphere of their PhD research $(33.3 \%)$ than those who took a course about the defense itself (18.2\%) and those who took no course $(6.5 \%)$.

For the majority of participants, regardless of the category of preparatory course, the defense did not influence their desire to work in academia. Those who took a module as part of another PhD course about the defense report a larger percentage of those whose desire to work in academia decreased due to the defense $(16.7 \%)$ than those who took a defense course $(9.1 \%)$ and those who took no course $(9.2 \%)$.

Table 19. Long-term impact of defense on student perception, by type of preparatory course before the defense.

\begin{tabular}{|c|c|c|c|}
\hline & Defense course & PhD course & no course \\
\hline \multicolumn{4}{|c|}{ How did your defense influence your perception of your academic competence? } \\
\hline & $n=11$ & $n=6$ & $n=185$ \\
\hline Increased & $54.6 \%$ & $50.0 \%$ & $57.3 \%$ \\
\hline Not affected & $18.2 \%$ & $50.0 \%$ & $34.6 \%$ \\
\hline Decreased & $27.3 \%$ & $0.0 \%$ & $8.1 \%$ \\
\hline \multicolumn{4}{|c|}{ How did your defense influence your desire to continue to work in the sphere of your PhD research } \\
\hline & $n=11$ & $n=6$ & $n=185$ \\
\hline Increased & $45.5 \%$ & $33.3 \%$ & $30.8 \%$ \\
\hline Not affected & $36.4 \%$ & $33.3 \%$ & $62.7 \%$ \\
\hline Decreased & $18.2 \%$ & $33.3 \%$ & $6.5 \%$ \\
\hline \multicolumn{4}{|c|}{ How did your defense influence your desire to work in academia? } \\
\hline & $n=11$ & $n=6$ & $n=185$ \\
\hline Increased & $27.3 \%$ & $33.3 \%$ & $28.1 \%$ \\
\hline Not affected & $63.6 \%$ & $50.0 \%$ & $62.7 \%$ \\
\hline Decreased & $9.1 \%$ & $16.7 \%$ & $9.2 \%$ \\
\hline \multicolumn{4}{|c|}{ How did your defense influence your perception on the publishability of your research? } \\
\hline & $n=11$ & $n=6$ & $n=185$ \\
\hline Increased & $45.5 \%$ & $33.3 \%$ & $38.4 \%$ \\
\hline Not affected & $36.4 \%$ & $33.3 \%$ & $54.1 \%$ \\
\hline Decreased & $18.2 \%$ & $33.3 \%$ & $7.6 \%$ \\
\hline
\end{tabular}

The relation between a preparatory defense course and the perceived publishability of the research is not clear. On one hand, a larger percentage of those who took a course about the defense perceive that the defense increased their perceived publishability of their research (45.5\%) than those who took a module in another PhD course $(33.3 \%)$ and those who did not take a course (38.4\%). Yet, at the same time, a larger percentage of those who took a module in another PhD course (33.3\%) report a decrease in perceived publishability of their research as a result of the defense than those who took a defense course $(18.2 \%)$ and those who did not take a preparatory course $(7.6 \%)$.

The reason why a course about the PhD defense does not seem to have a positive effect on the perception of the doctoral candidates is not explored in this study. However, I can speculate about possible reasons. First of all, as indicated in Table 9, there is a link 
between preparatory actions, country of defense, and thus defense format. As such, the sentiment may be more influenced by the defense format than by the preparatory actions. It is also possible that those who feared the defense most are the candidates who sought out preparatory courses. Secondly, we observe slightly more positive outcomes for those who took a module about the doctoral defense as part of a general $\mathrm{PhD}$ course in some categories. Here, I speculate that those who have been taking a general $\mathrm{PhD}$ course have been supported throughout their entire doctoral journey in terms of the process of doing doctoral research, and this support has reflected positively on the sentiment in relation to the defense. Finally, it is important to note that preparatory courses may be designed with the best intentions in mind, but may miss the mark, as they may not be aligned with the needs of the doctoral candidates, may potentially be compulsory at the institution without the candidate being interested in the course, or may not be updated based on outcomes and feedback of doctoral candidates after the defense.

It is important to repeat again the low number of participants who took a course about the defense: 11 participants took a course about the defense itself and 6 respondents took it as part of another PhD course. The vast majority of respondents $(91.6 \%)$ did not attend a course to prepare for the defense. As such, it is difficult to draw conclusions based on the low number of respondents. In conclusion, there is no marked clear positive influence of taking a course on the sentiments during the defense and the long-term impact. However, there are some indications that preparing doctoral candidates for the defense with a course can be positive. Here, it is important that such a course is aligned with the doctoral defense format, the overall doctoral education program, and that it can serve to clarify doubts students may have about the defense.

\subsubsection{Association between preparatory reading and perception}

The last aspect of defense preparation is whether the respondent read a book, a chapter, websites or blog posts about the defense as part of their preparation, and the relation of this aspect to the perception during and after the defense.

There is no statistically significant relation or difference in mean values between the respondents who read in preparation and those who did not in terms of nervousness before and during the defense, or after the defense while waiting for the outcome. Similarly, there is no statistically significant relation or difference in mean values between the respondents who read in preparation and those who did not in terms of enjoyment, perceived seriousness, perceived formality, and perceived difficulty of the defense.

When it comes to the perceived importance of the defense, we can find that there is a weak correlation ( $p=0.0727)$ with preparatory reading. Those who prepared by reading rated the perceived importance of the defense higher (mean $=8.20)$ than those who did not (mean = 7.25), see Figure 4a. A potential explanation for this observation is that those who read about the defense in preparation understood better the weight and importance of the event.

Those who prepared for the defense by reading rated the overall value of the defense (mean $=7.65$ ) in the same way as those who did not read in advance (mean $=7.41$ ). This observation is also reflected by the boxplot in Figure $4 \mathrm{~b}$. 


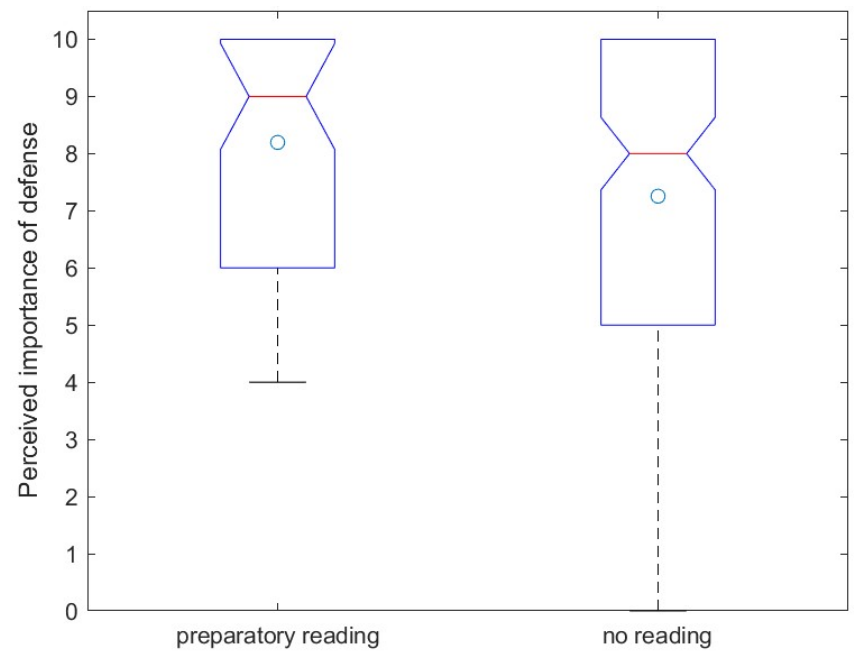

(a)

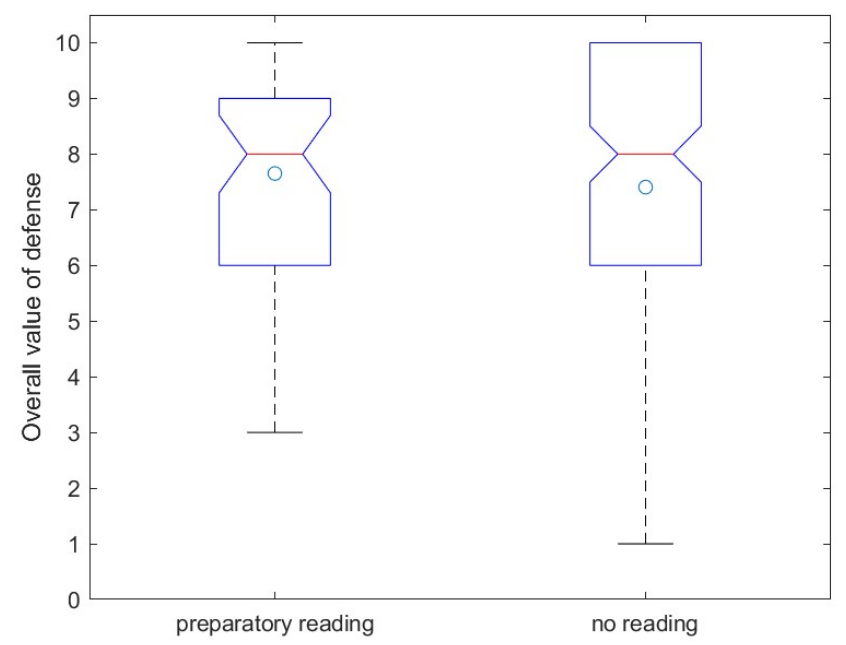

(b)

Figure 4. Influence of preparatory reading before the defense on (a) perceived importance of the defense, (b) overall value of the defense. $n=202$

In terms of perceived committee fairness and suitability, the results in Table 20 show that there is not much difference between the respondents who read in preparation and those who did not. In terms of committee fairness, a slightly larger percentage of respondents who did not prepare by reading $(85.1 \%)$ considered their committee fair than those who prepared by reading $(80.4 \%)$, and similarly a larger percentage of respondents who did not prepare by reading (81.4\%) considered their committee suitable for making a wellbalanced assessment of the work than those who prepared by reading (73.9\%). A possible explanation here is that those candidates who, prior to the defense, worried about the fairness and suitability of their committee, spent more time trying to find information about the defense from book sources and online.

Table 20. Committee fairness and suitability, by preparatory reading before the defense.

\begin{tabular}{|c|c|c|}
\hline & Yes & No reading \\
\hline \multicolumn{3}{|c|}{ Did you consider your committee fair? } \\
\hline & $n=46$ & $n=154$ \\
\hline Yes & $80.4 \%$ & $85.1 \%$ \\
\hline To some extent & $19.6 \%$ & $13.6 \%$ \\
\hline No & $0.0 \%$ & $1.3 \%$ \\
\hline \multicolumn{3}{|c|}{ Did you consider your committee suitable for making a well-balanced assessment of your work? } \\
\hline & $n=46$ & $n=156$ \\
\hline Yes & $73.9 \%$ & $81.4 \%$ \\
\hline To some extent & $23.9 \%$ & $17.3 \%$ \\
\hline No & $2.2 \%$ & $1.3 \%$ \\
\hline
\end{tabular}

Table 21 shows the breakdown of the perceived purpose of the defense by categories of preparatory reading before the defense. From these results, we can see that in terms of perceived purpose, there is no difference between those respondents who prepared by reading as compared to those who did not. Similarly, Table 22 shows that the long-term impact of the defense does not differ between those who prepared by reading and those who did not.

In conclusion, these analyses show that the influence of reading about the defense as part of the preparation does not impact student perception. A possible explanation why preparatory reading does not seem to have a significant positive impact on student perception during the defense and long term is that the sources are not tailored to the defense 
format. For example, a doctoral candidate in the Netherlands, where the defense takes place after publication of the thesis, is public, and involves a large committee, may find information online or in books about the viva in the United Kingdom, where the defense takes place before the publication of the thesis, determines the level of corrections necessary, is private, and involves only two committee members as examiners. Such information is not in line with the defense format, and thus does not serve as good preparatory information.

Table 21. Perceived purpose of the defense, by preparatory reading before the defense. Participants were asked to check all that apply, so reported values of $n$ are the number of responses of all checked answers together, not the individual respondents.

\begin{tabular}{ccc}
\hline & Yes & No reading \\
& $n=131$ & $n=405$ \\
\hline Examination & $31.3 \%$ & $28.9 \%$ \\
Ceremony & $14.5 \%$ & $16.3 \%$ \\
Celebration & $11.5 \%$ & $13.3 \%$ \\
Confirmation & $19.1 \%$ & $19.8 \%$ \\
Rite of passage & $19.9 \%$ & $19.5 \%$ \\
Other & $3.8 \%$ & $2.2 \%$ \\
\hline
\end{tabular}

Table 22. Long-term impact of defense on student perception, by type of preparatory course before the defense.

\begin{tabular}{ccc}
\hline & Yes & No reading \\
\hline How did your defense influence your perception of your academic competence? & $n=46$ & $n=156$ \\
Increased & $58.7 \%$ & $56.4 \%$ \\
Not affected & $32.6 \%$ & $34.6 \%$ \\
Decreased & $8.7 \%$ & $9.0 \%$ \\
\hline How did your defense influence your desire to continue to work in the sphere of your PhD research? & $n=156$ \\
& $n=46$ & $30.77 \%$ \\
Increased & $34.8 \%$ & $61.5 \%$ \\
Not affected & $56.5 \%$ & $7.7 \%$ \\
Decreased & $8.7 \%$ & $n=156$ \\
How did your defense influence your desire to work in academia? & $27.6 \%$ \\
& $n=46$ & $62.2 \%$ \\
Increased & $30.4 \%$ & $10.3 \%$ \\
Not affected & $63.0 \%$ & $n=156$ \\
Decreased & $6.5 \%$ & $37.8 \%$ \\
How did your defense influence your perception on the publishability of your research? & $n=46$ & $53.9 \%$ \\
Increased & $41.3 \%$ & $8.3 \%$ \\
Not affected & $47.8 \%$ & \\
Decreased & $10.9 \%$ & \\
\hline
\end{tabular}

\section{Discussion}


As reflected by the story of the viva where the candidate almost failed [1], understanding the purpose of the defense, and the behavior expected from the candidate is an important step in the preparation of the defense. A similar observation was made by Wellington [6], who found that some students had erroneous conceptions of the purpose of the defense. Since this type of preparation draws on tacit assumptions of behavior [47], it may not be a tangible aspect of preparing for the defense. Indeed, only two respondents of this study's survey mentioned that understanding the defense proceedings itself was part of their preparation. One respondent mentioned reviewing the defense proceedings, and one mentioned aspects of protocol. As such, doctoral candidates may need more support in terms of understanding the defense format and what is expected during the defense.

One preparatory step that is often cited in the literature [48] is to read the thesis carefully prior to the defense. Familiarizing oneself with the contents of the thesis prior to the defense is an important step towards being able to defend the thesis. Failing to know the contents of the thesis may lead to questions about the authorship of the written thesis. The importance of this preparatory step is also reflected in the outcomes of this study's survey. Reading the thesis was the second most frequently mentioned aspect of preparation in the open-ended question about preparing for the defense.

From the outcomes of this study and from the literature review [3, 24], I conclude that having a mock defense generally has a positive impact on student perception of the doctoral defense. In the research by Share [25], 25\% of the candidates had a mock defense, and in this survey $33.7 \%$ of the respondents had a mock defense before the defense. This finding could indicate that using a mock defense as practice before the defense has become more common over the past years. One caveat with the mock defense is that, as identified by Watts [24], the mock defense requires effort in the department so that an environment can be created that is as similar as possible to the actual defense.

The analysis of the survey results showed that a preparatory course can help doctoral candidates prepare for the defense, but at the same time sometimes seems to miss the mark. In the study by Wellington [6], it was clear that students appreciate a preparatory course. For those designing courses for doctoral candidates to prepare for the defense, it is important to align such a course with the format of the defense at the institution. A generic course that is not tailored to the defense format will not help doctoral candidates understand the purpose of the defense and how to best prepare for it. Moreover, interviews with students after the defense should be used to identify aspects that are important in such a course, and for those students who took the course, such an interview should include feedback on the course. With this input, the course can be continually improved.

I included reading books, chapters, blogs, and other sources as a category of preparation in this survey, as Share [25] found that $47 \%$ of doctoral candidates who participated in her survey from the United Kingdom rely on $\mathrm{PhD}$ advice books as a source of information about the doctoral defense. In my study, I found that $22.8 \%$ of respondents, from an international population, consulted books, chapters, and blogs to prepare for the defense. However, in Table 12, we can see that $45.8 \%$ of the respondents from the UK in this study consulted books, chapters, and blogs, and this percentage is very similar to that found by Share [25]. The difference in percentage is similar to the differences found with regard to using a preparatory course, Table 9, where a larger percentage of participants from the UK participated in a preparatory course. In this study, I found no indications that preparatory reading is an effective defense preparation measure. A possible explanation of this outcome is that simply looking for information on the doctoral defense online will give a variety of sources. These sources will not all be tailored to the defense format used in the university of the doctoral candidate, and as such may not contain relevant information. For example, looking up advice on how to prepare for the doctoral defense may include the recommendation of summarizing each page of the thesis into one line. This advice works well for those who prepare for the UK-style viva, where the examiners may decide to go through the thesis on a page by page basis. On the other hand, this 
advice does not serve those who have a public defense with a large committee asking broad questions as is common in continental Europe.

My recommendation based on this study is for universities individually to assess how they can best support their doctoral candidates towards the defense. Before introducing a general policy of using a mock defense and/or a preparatory course, I recommend to run a pilot on a subset of doctoral candidates of a cohort within one semester, for example. After the defense of all candidates, I recommend to carry out an exit interview about the defense and the student's preparation, and what their reflections in hindsight. For the subset who participated in the pilot course, their feedback on the pilot and how it helped them prepare for the defense or not, should be included as well. With this input information, the measures can be evaluated and continually improved to the point where university-wide adoption can become a good policy.

At the same time, it is important to understand that doctoral candidates who are ready to defend are independent researchers. They have spent years developing their methods of planning and executing their research [49]. Offering all candidates the same preparation path may thus be counterintuitive. This observation aligns with what Watts [24] remarked as "Also, of course, students are highly individual, with each having their preferred ways of approaching the preparation task." From that perspective, and given the more muddled outcomes of this research, individual preparation tracks may be the best option. Such tracks could consist of an intake meeting with student and a person from the doctoral school to identify the particular needs of the candidate, which could range from the need to better understand the defense format or the expectations, over a desire to practice through a mock defense, to help dealing with potential anxiety around the defense.

\section{Conclusions}

This article explores how preparing for the doctoral defense impacts the outcome of the defense and the perception of the student about the doctoral defense experience. I studied three aspects of preparation in a quantitative way: having a mock defense, having a preparatory course for the defense, and reading books, blogs, and other sources in preparation for the defense. I found that a little over half of the respondents had either a mock defense or another type of practice for the defense. Less than $10 \%$ of the respondents attended a course in preparation of their defense: either as a course dedicated to preparing for the defense, or as part of a general PhD course. About a quarter of the respondents read books, chapters, blog posts or other sources in preparation for the defense.

In addition, I used open-ended questions to qualitatively analyze how doctoral candidates prepare for the defense, and what they wish they would have done differently. The most common methods doctoral candidates use to prepare for the defense are making the presentation, reading the thesis, and practicing for the defense. About half of the respondents to the open-ended question indicated they would not have prepared differently for the defense. Those who would have done something differently in hindsight most commonly state they would have prepared more, or would have gone into the defense with a different mindset: with less stress, or with more confidence, or taking the defense as a more formal event that requires style and salesmanship.

From the quantitative analysis and literature review, I draw the following conclusions with regard to the different types of preparation:

- A mock defense seems to be good practice, but requires time and effort to be set up in such a way that it is as similar to the defense as possible.

- A preparatory course can have a positive effect, but sometimes it seems to miss the mark. A proper design of such courses and frequent updating with feedback from the candidates is important here.

- Reading books, blogs, and chapters seems to be less of an effective preparatory measure. A possible reason here is that information on the topic is widely available online, but that the doctoral candidate needs to filter which information is relevant for their defense format. 
Based on the analysis of the survey data and the available literature, I can give the following two recommendations:

- Doctoral candidates may need more support in terms of understanding the format of their defense, and what to expect during the defense.

- Universities should explore together with their doctoral candidates and supervisors what would work best to prepare their candidates for the defense. Options include university-wide adoption of measures such as a mock defense and/or a preparatory course, as well as individual paths tailored to the needs of each candidate separately.

Author Contributions: The author confirms being the sole author of this work.

Funding: This research received no external funding

Data Availability Statement: The dataset generated by this research is available in the public domain: https://doi.org/10.5281/zenodo.5045412

Acknowledgments: I'd like to thank the participants who responded to my questionnaire about doctoral defense formats.

Conflicts of Interest: The author declares no conflict of interest.

\section{References}

1. Remenyi, D. "Never smile at a crocodile: A bad viva voce by the rule book " The Electronic Journal of Business Research Methods 17 (2019): 67-73.

2. $\quad$ Davis, G. and H. Engward. "In defence of the viva voce: Eighteen candidates' voices." Nurse Education Today 65 (2018): 30-35. https://doi.org/10.1016/j.nedt.2018.01.038. http://www.sciencedirect.com/science/article/pii/S0260691718300698.

3. $\quad$ Manidis, M. and R. Addo. "Learning a practice through practise: Presenting knowledge in doctoral spoken presentations." Studies in Continuing Education 39 (2017): 235-50. 10.1080/0158037X.2017.1306504. https://doi.org/10.1080/0158037X.2017.1306504.

4. Doloriert, C. and S. Sambrook. "Accommodating an autoethnographic phd: The tale of the thesis, the viva voce, and the traditional business school." Journal of Contemporary Ethnography 40 (2011): 582-615. 10.1177/0891241610387135. https://journals.sagepub.com/doi/abs/10.1177/0891241610387135.

5. Crossouard, B. "The doctoral viva voce as a cultural practice: The gendered production of academic subjects." Gender and Education 23 (2011): 313-29. 10.1080/09540253.2010.508453. https://doi.org/10.1080/09540253.2010.508453.

6. Wellington, J. "Supporting students' preparation for the viva: Their pre-conceptions and implications for practice." Teaching in Higher Education 15 (2010): 71-84. 10.1080/13562510903487867. https://doi.org/10.1080/13562510903487867.

7. Markulis, P. M. and D. R. Strang. "'Viva voce": Oral exams as a teaching \& learning experience." Development in Business Simulation and Experiential Learning 35 (2008): 118-27.

8. Morley, L., D. Leonard and M. David. "Variations in vivas: Quality and equality in british phd assessments." Studies in Higher Education 27 (2002): 263-73. 10.1080/03075070220000653. https://doi.org/10.1080/03075070220000653.

9. Morley, L., D. Leonard and M. David. "Quality and equality in british phd assessment." Quality Assurance in Education 11 (2003): 64-72. doi:10.1108/09684880310471489. https://www.emeraldinsight.com/doi/abs/10.1108/09684880310471489.

10. Goulding, N. J. and A. Geraghty. "Standards for phd education in pharmacology in the uk." Turkish Journal of Biochemistry 36 (2011): $19-25$.

11. Golding, C., S. Sharmini and A. Lazarovitch. "What examiners do: What thesis students should know." Assessment \& Evaluation in Higher Education 39 (2014): 563-76. 10.1080/02602938.2013.859230. https://doi.org/10.1080/02602938.2013.859230.

12. Carter, S. "English as an additional language (eal) viva voce: The eal doctoral oral examination experience." Assessment $\mathcal{E}$ Evaluation in Higher Education 37 (2012): 273-84. 10.1080/02602938.2010.528555. https://doi.org/10.1080/02602938.2010.528555.

13. Barnett, J. V., R. A. Harris and M. J. Mulvany. "A comparison of best practices for doctoral training in europe and north america." FEBS open bio 7 (2017): 1444-52. 10.1002/2211-5463.12305. https://www.ncbi.nlm.nih.gov/pubmed/28979835

https://www.ncbi.nlm.nih.gov/pmc/articles/PMC5623696/.

14. Kyvik, S. "Assessment procedures of norwegian phd theses as viewed by examiners from the USA, the uk and sweden." Assessment \& Evaluation in Higher Education 39 (2014): 140-53. 10.1080/02602938.2013.798395. https://doi.org/10.1080/02602938.2013.798395.

15. LERU. Doctoral studies in europe: Excellence in researcher taining. Leuven, Belgium: LERU, 2007,

16. Pitskhelauri, N., N. Chikhladze and A. Tsiskaridze. "New paradigm of phd education at tbilisi state university faculty of medicine in georgia." Turkish Journal of Biochemistry 36 (2011): 82-86.

17. Petkova, D. "Phd education in bulgaria." Turkish Journal of Biochemistry 36 (2011): 45-48.

18. van der Ploeg, I. "Quality assurance in doctoral education experiences from karolinska institutet." Turkish Journal of Biochemistry 36 (2011): 67-68. 
19. Gurevich, K. G. and N. D. Yushuk. "System of research staff training in russian federation." Turkish Journal of Biochemistry 36 (2011): 31-34.

20. Jackson, C. and P. Tinkler. "Back to basics: A consideration of the purposes of the phd viva." Assessment E Evaluation in Higher Education 26 (2001): 355-66. 10.1080/02602930120063501. https://doi.org/10.1080/02602930120063501.

21. Lantsoght, E. O. L. "Students' perceptions of doctoral defense formats." Education Sciences 11 (2021): 519. https://www.mdpi.com/2227-7102/11/9/519.

22. Shimabukuro, K. "Phd defenses around the world: A defense from literature at the university of new mexico " PhD Talk, 2018. https://www.evalantsoght.com/2018/02/phd-defenses-around-the-world-a-defense-from-literature-at-the-university-of-new-mexico.html.

23. Abambres, M. "Phd defenses around the world: A defense in portugal." PhD Talk, 2019. https://www.evalantsoght.com/2019/03/phd-defenses-around-the-world-a-defense-in-portugal.html.

24. Watts, J. H. "Preparing doctoral candidates for the viva: Issues for students and supervisors." Journal of Further and Higher Education 36 (2012): 371-81. 10.1080/0309877X.2011.632819. https://doi.org/10.1080/0309877X.2011.632819.

25. Share, M. "The phd viva: A space for academic development." International Journal for Academic Development 21 (2016): 178-93. 10.1080/1360144X.2015.1095759. https://doi.org/10.1080/1360144X.2015.1095759.

26. Lantsoght, E. O. L. "Students' perceptions of doctoral defense in relation to sociodemographic characteristics." Education Sciences 11 (2021): 463. https://www.mdpi.com/2227-7102/11/9/463.

27. Leung, S. O. "A comparison of psychometric properties and normality in 4-, 5-, 6-, and 11-point likert scales." Journal of Social Service Research 37 (2011): 412-21. 10.1080/01488376.2011.580697. $\quad$ https://www.scopus.com/inward/record.uri?eid=2-s2.079960784266\&doi $=10.1080 \% 2 \mathrm{f} 01488376.2011 .580697 \&$ partnerID $=40 \& \mathrm{md} 5=0$ facfee0f0c3b0343f6313114f8009dd.

28. The Mathworks, I. Matlab r2019a, user's guide. Natick, USA: 2019,

29. Jamieson, S. "Likert scales: How to (ab)use them." Medical Education 38 (2004): 1217-18. https://doi.org/10.1111/j.13652929.2004.02012.x. https://onlinelibrary.wiley.com/doi/abs/10.1111/j.1365-2929.2004.02012.x.

30. Kilty, T. J. and A. C. Burrows. "Secondary science preservice teachers' perceptions of engineering: A learner analysis." Education Sciences 9 (2019): 29. https://www.mdpi.com/2227-7102/9/1/29.

31. Braun, V. and V. Clarke. "Using thematic analysis in psychology." Qualitative Research in Psychology 3 (2006): 77-101. 10.1191/1478088706qp063oa. https://www.tandfonline.com/doi/abs/10.1191/1478088706qp063oa.

32. Lofland, J., D. A. Snow, L. Anderson and L. H. Lofland. Analyzing social settings: A guide to qualitative observation and analysis. Belmont, USA: Wadsworth, 2006,

33. Huppatz, K., K. Sang and J. Napier. "'If you put pressure on yourself to produce then that's your responsibility': Mothers' experiences of maternity leave and flexible work in the neoliberal university." Gender, Work E Organization 26 (2019): $772-88$. 10.1111/gwao.12314. https://onlinelibrary.wiley.com/doi/abs/10.1111/gwao.12314.

34. Lantsoght, E. O. L. Dataset doctoral defenses and defense formats. Zenodo: 2021,

35. Lantsoght, E. O. L. "Students' perception of doctoral defense formats." Education Sciences (in review):

36. NUI Galway. "Phd viva guide." 2012. https:/www.nuigalway.ie/graduate-studies/currentstudents/viva/. 2021.

37. Lantsoght, E. O. L. "Phd talk " 2021. https://www.evalantsoght.com/blog.html. 2021.

38. Thomson, P. "Patter." 2021. https://patthomson.net/. 2021.

39. Mewburn, I. "The thesis whisperer." 2021. https://thesiswhisperer.com/. 2021.

40. GradHacker. "Gradhacker." GradHacker. 2016. https://www.insidehighered.com/blogs/gradhacker.

41. Kelsky, K. "The professor is in." 2021. https://theprofessorisin.com/. 2021.

42. Ryder, N. "Viva survivors." 2021. http://viva-survivors.com/. 2021.

43. Phillips, E. and D. S. Pugh. How to get a phd a handbook for students and their supervisors. 5th. Maidenhead: Open University Press, 2010, 1 online resource (xvi, 258 p.).

44. Lantsoght, E. O. L. The a-z of the phd trajectory - a practical guide for a succesful jurney. Cham, Switzerland: Springer, 2018,

45. Murray, R. How to survive your viva: Defending a thesis in an oral examination (uk higher education oup humanities $\mathcal{E}$ social sciences study skills) 3rd edition. Open University Press, 2015, 194.

46. Murray, R. How to survive your viva: Defending a thesis in an oral examination. Open University Press, 2015,

47. Trafford, V. and S. Leshem. "Anatomy of a doctoral viva." Journal of Graduate Education 3 (2002): 33-40.

48. Brennan, N. "100 phd rules of the game to successfully complete a doctoral dissertation." Accounting, Auditing E Accountability Journal 32 (2019): 364-76. doi:10.1108/AAAJ-01-2019-030. https://www.emeraldinsight.com/doi/abs/10.1108/AAAJ-01-2019-030.

49. Kamler, B. and P. Thomson. "The failure of dissertation advice books: Toward alternative pedagogies for doctoral writing." Educational Researcher 37 (2008): 507-14. http://www.jstor.org.tudelft.idm.oclc.org/stable/25209042. 